\title{
Assessing the Application-Specific Substitutability of Lithium-Ion Battery Cathode Chemistries Based on Material Criticality, Performance, and Price
}

\author{
Steffen Kiemel $^{1, *}$, Simon Glöser-Chahoud ${ }^{2} \mathbb{D}$, Lara Waltersmann ${ }^{1} \mathbb{D}$, Maximilian Schutzbach ${ }^{1,3}$, \\ Alexander Sauer ${ }^{1,3}$ and Robert Miehe ${ }^{1}$ (D) \\ 1 Fraunhofer Institute for Manufacturing Engineering and Automation IPA, Nobelstraße 12, 70569 Stuttgart, \\ Germany; lara.waltersmann@ipa.fraunhofer.de (L.W.); \\ maximilian.schutzbach@ipa-extern.fraunhofer.de (M.S.); alexander.sauer@ipa.fraunhofer.de (A.S.); \\ robert.miehe@ipa.fraunhofer.de (R.M.) \\ 2 Institute for Industrial Production IIP, Karlsruhe Institute of Technology, Hertzstraße 16, 76187 Karlsruhe, \\ Germany; simon.gloeser-chahoud@kit.edu \\ 3 Institute for Energy Efficiency in Production EEP, University of Stuttgart, Nobelstraße 12, \\ 70569 Stuttgart, Germany \\ * Correspondence: steffen.kiemel@ipa.fraunhofer.de
}

Citation: Kiemel, S.; GlöserChahoud, S.; Waltersmann, L.; Schutzbach, M.; Sauer, A.; Miehe, R. Assessing the Application-Specific Substitutability of Lithium-Ion Battery Cathode Chemistries Based on Material Criticality, Performance, and Price. Resources 2021, 10, 87. https://doi.org/10.3390/ resources10090087

Academic Editors: Andrea Thorenz and Armin Reller

Received: 30 July 2021

Accepted: 19 August 2021

Published: 25 August 2021

Publisher's Note: MDPI stays neutral with regard to jurisdictional claims in published maps and institutional affiliations.

Copyright: (c) 2021 by the authors. Licensee MDPI, Basel, Switzerland. This article is an open access article distributed under the terms and conditions of the Creative Commons Attribution (CC BY) license (https:// creativecommons.org/licenses/by/ $4.0 /)$.

\begin{abstract}
The material use of lithium-ion batteries (LIBs) is widely discussed in public and scientific discourse. Cathodes of state-of-the-art LIBs are partially comprised of high-priced raw materials mined under alarming ecological and social circumstances. Moreover, battery manufacturers are searching for cathode chemistries that represent a trade-off between low costs and an acceptable material criticality of the comprised elements while fulfilling the performance requirements for the respective application of the LIB. This article provides an assessment of the substitutability of common LIB cathode chemistries (NMC 111, -532, -622, -811, NCA 3\%, -9\%, LMO, LFP, and LCO) for five major fields of application (traction batteries, stationary energy storage systems, consumer electronics, power-/garden tools, and domestic appliances). Therefore, we provide a tailored methodology for evaluating the substitutability of products or components and critically reflect on the results. Outcomes show that LFP is the preferable cathode chemistry while LCO obtains the worst rating for all fields of application under the assumptions made (as well as the weighting of the considered categories derived from an expert survey). The ranking based on the substitutability score of the other cathode chemistries varies per field of application. NMC 532, $-811,-111$, and LMO are named recommendable types of cathodes.
\end{abstract}

Keywords: lithium-ion battery; LIB; raw material criticality; substitutability; cathode chemistries; traction batteries; stationary energy storage systems; consumer electronics; power-/garden tools; domestic appliances

\section{Introduction}

Tackling climate change and decarbonizing the economy and society may be considered as some of the greatest challenges of this century. The Paris Agreement limits global warming to 1.5 degrees [1]. The European Union aims to achieve climate neutrality by 2050 [2]. This results in massive pressure for technology development and applications in industries. One of the most promising solutions for achieving climate neutrality is electrification in combination with the expansion of renewable energies. With the recent proposal "Fit-for-55" within its Green Deal Framework, the European Commission has significantly increased the need for electrification, especially in the transport sector [3]. Emissions trading is to be introduced for road traffic and only new registrations of zeroemission cars are to be allowed from 2035 onwards. Therefore, electrification will be the key measure for reaching the climate targets. This results in a significantly increasing 
demand for batteries. In this context, lithium-ion batteries (LIBs) are of utmost importance due to their rechargeability and favorable performance properties. LIBs cover a wide range of applications, such as traction batteries, stationary energy storage systems, consumer electronics, power/garden tools, and domestic appliances. Traction batteries for electric vehicles represent a huge amount of potential for achieving climate goals, as road transport is responsible for approximately $15 \%$ of global $\mathrm{CO}_{2}$ emissions [4]. Electrified transport in combination with a low-carbon energy supply can reduce these $\mathrm{CO}_{2}$ emissions significantly. According to Zhang and Fujimori, the $\mathrm{CO}_{2}$ emissions of this sector can be reduced by $50 \%$ until 2050 only via electrification [5]. The International Energy Agency (IEA) even states that the $\mathrm{CO}_{2}$ emissions from road transport may be reduced to zero for light commercial vehicles, passenger cars, and buses by 2070 [6]. In addition, batteries can be used as stationary energy storage by private, commercial, or utility users, and thus balance wind or solar energy shortages and contribute to energy flexibility [7].

To cover the huge range of applications of LIBs, different cathode chemistries are used. These include "Lithium Nickel Manganese Cobalt Oxide" (NMC 111, NMC 532, NMC 622, and NMC 811), "Lithium Nickel Cobalt Aluminum Oxide" (NCA 3\% Co and NCA 9\% Co), "Lithium Iron Phosphate" (LFP), "Lithium Cobalt Oxide (LCO), and "Lithium Manganese Oxide" (LMO) [8]. The well-established alphabetic abbreviations denote the elements the cathodes are comprised of. The stated numbers define the mass percentages of the respective materials. For example, the label NMC 532 indicates that the cathode comprises five parts nickel, three parts manganese, and two parts cobalt. The percentage after the code NCA (nickel cobalt aluminum oxide) describes the material share of cobalt within the cathode [9].

As shown by Merriman, the market share of the different cathode chemistries will change in favor of higher energy density material compositions with the additional advantages of lower costs and higher social acceptance [8]. This means that cathode chemistries with higher nickel content are likely to increase their market share significantly, while cathode chemistries with higher cobalt content are predicted to decline to a market share of less than $10 \%$ in 2025 [8].

This paper focuses on cathode chemistries that either already have a high market share or will be important in the near future. Thus, solid-state batteries and other innovative cell generations, such as lithium air, are neglected, although they are expected to gain significant market shares in the future [9]. This is because no market-ready battery has been developed yet and, according to forecasts, they will initially become relevant in 2030 [9]. For the battery industry, such forecasts are very important for strategically planning the production infrastructure and portfolio. This article will provide an additional approach to such considerations. By assessing the substitutability of cathode chemistries, decisionmakers in industries receive a detailed overview of the potential benefits and disadvantages of staying with the existing product portfolio or changing to another.

One of the critical factors for the market penetration of LIBs is the low security of cathode materials [10]. In order to assess impact factors for a sustainable supply of resources, the holistic methodology of resource criticality assessments was developed a few years ago. The first criticality assessments were conducted in the context of both world wars to evaluate strategically valuable resources [11]. While these studies usually concentrated on minerals, later analyses have significantly broadened the scope.

According to the standard denotation by Erdmann and Graedel, a critical raw material is defined as one for which the medium to long-term supply situation might turn out to be critical from the point of view of various systems (e.g., companies, industries, national economies) [12]. This article focuses on the company perspective, for which various authors have developed respective models and methodologies [13-15]. Schrijvers et al. provide a comprehensive overview [16]. In the case of an indicator-based criticality assessment, this is carried out based on different dimensions such as vulnerability, supply risk, environmental impact, and social implications $[13,14]$. Each dimension is assessed quantitatively using various indicators. Qualitative information (e.g., concerning recyclability) is transformed 
to a quantitative scale where possible. There are various approaches to interpreting the results. While it is possible to aggregate the individual results of the considered indicators to calculate an overall criticality value, some studies remain on the indicator level, since this allows for detailed analyses of potential problems in the supply chain of raw materials.

Due to the limited nature of raw materials, criticality assessments have been extensively investigated in the recent literature. Among others, numerous commodity-specific analyses have been performed for metals and metalloids [17-20], such as copper [21], iron [22], and rare earth elements [23]. However, the analysis of raw material criticality is an ongoing process since the respective methodologies are continually being improved and further possible indicators integrated. Furthermore, results may vary significantly depending on the underlying base year of the utilized data. A prominent example of such variations in results for individual indicators is the significant increase in the static reach of lithium due to the exploitation of wider reserves within the past few years [24,25]. Furthermore, demand impulses through new emerging technologies should be mentioned here. In addition to the consideration of individual elements, an aggregated consideration of criticality at the product or technology level is also possible. Exemplarily for this context, specific use cases for clean energy technologies [26], such as photovoltaics [27] and water electrolyzers [28], and other emerging technologies [29] have been described. A few criticality analyses have also been carried out for different battery technologies $[9,30,31]$ and energy storage systems [32].

Nevertheless, the results from previous studies cannot be adopted, since in this paper, substitutability is not implicitly analyzed in the vulnerability dimension, but explicitly as the main finding quantified with a separate set of indicators and criteria. Furthermore, in addition to supply risk, the other dimensions of environmental impact and social implications, according to Kolotzek et al. [14], are included to generate an overview of resource criticality that is as comprehensive as possible [33]. The combination of classic approaches to criticality assessments and methods from the fields of life cycle analysis as well as social life cycle analysis [14] results in an evaluation of the effects of resource use that involves all three pillars of sustainability (economic, environmental, social). To guarantee a consistent approach, all battery raw materials must be evaluated again according to the corresponding methodology.

In general, the substitution of single raw materials can lead to a significant decrease in the overall criticality of a material compound or a product/technology, respectively. However, this is not possible for complex technology components such as those of LIBs. Pivotal examples are the cathodes of LIBs, as they are comprised of various materials that cannot be individually substituted. Hence, the substitutability has to be analyzed on a composite, rather than on an elemental, level. As individual fields of applications are defined by specific requirements, this evaluation needs to be conducted in an applicationspecific manner. The present article provides a respective methodology. Consequently, the central research question is defined as: "Which LIB cathode chemistry is to be suggested for the considered fields of application, and what are the respective benefits when switching from the status quo to another cathode chemistry?".

This paper's contribution to the existing literature on raw material criticality assessment, substitutability, and, consequently, sustainability is twofold. First, we provide a comprehensive approach to how the substitutability of materials at a technology level could be quantified as an enhancement of basic criticality assessments. Second, we apply the methodology to current LIB chemistries as one of the most relevant emerging technologies in the debate about future material availability from a company perspective. Substitutability in many cases is included in the vulnerability score as a single sub-indicator for each raw material $[20,34,35]$. However, this is not sufficient to provide decision support at the firm level, where individual alternative technologies and material systems need to be compared. 


\section{Materials and Methods}

The methodology is separated into two main modules: (1) the assessment of material criticality; and (2) the determination of substitutability. For the latter, the two considered categories of price and performance are described, and the methodological approach in merging the individual results is outlined (Figure 1).

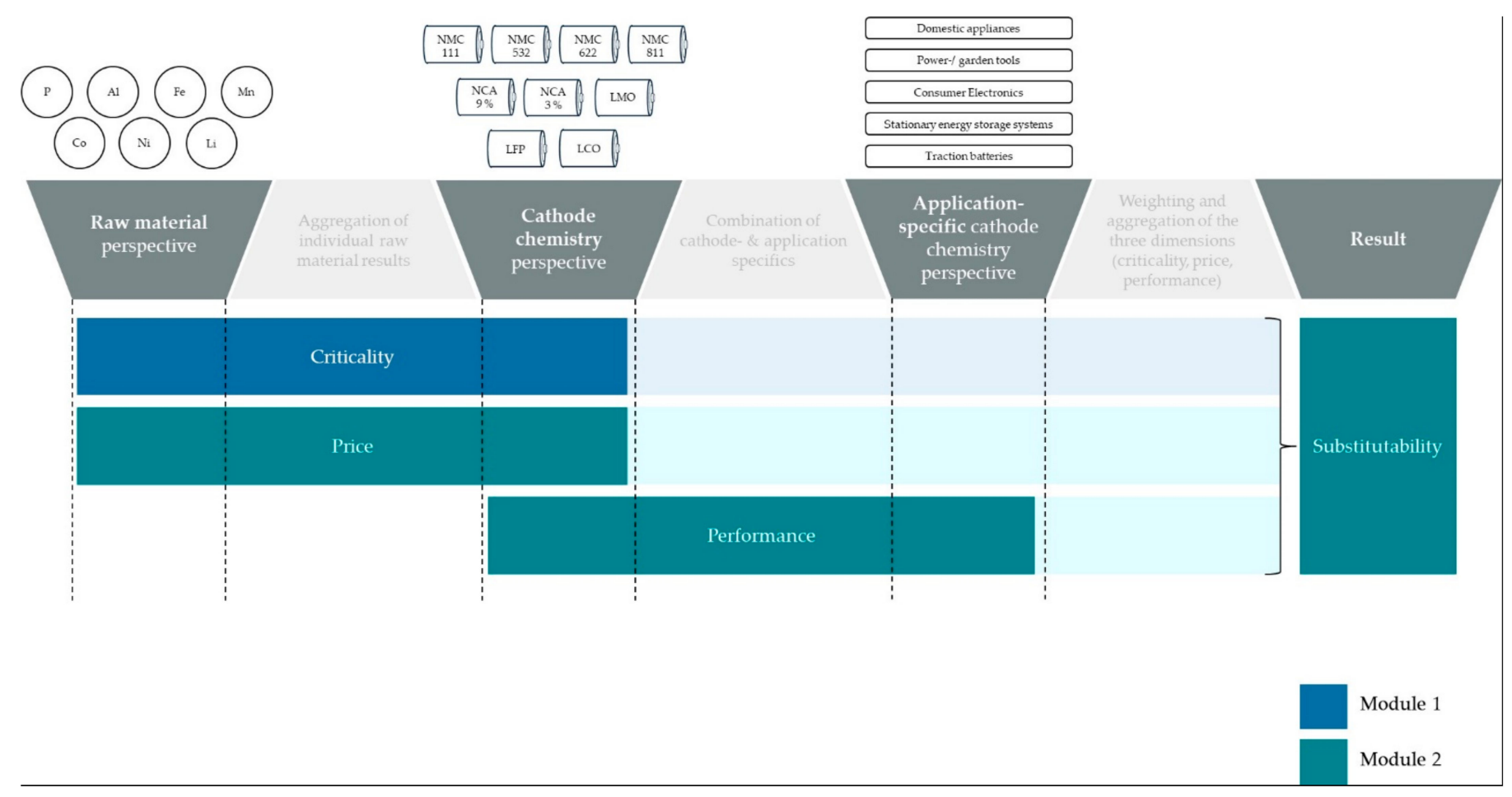

Figure 1. Visualization of the methodological approach.

The scope of the presented research includes nine different LIB cathode compositions. The respective selection illustrated in Figure 1 is based on state-of-the-art LIBs that either had, currently have, or are expected to gain relevant shares of the global LIB market $[8,9]$. As this article focuses on LIBs, each considered cathode chemistry comprises derivates of lithium, regardless of whether it is indicated in the abbreviation (L) or not. Thereby, the share of lithium in the cathode composition remains constant for all versions of NMC and NCA LIBs [8]. For assessing the raw material criticality of the considered cathode chemistries, the contained elements are individually assessed and later on aggregated by their material shares. The article focuses on cathode or so-called active materials and neglects other materials a LIB cell is comprised of.

The substitutability is assessed for five product families or fields of application (electric vehicles, stationary energy storage, consumer electronics, power-/garden tools, and domestic appliances). The respective choice is adopted from Full et al., who define the mentioned product families as the most popular use cases for LIBs regarding market shares based on available market analytics [36].

\subsection{Methodology of Criticality Assessment}

One of the most prominent approaches to criticality assessment is based on the work of Graedel et al. Thereby, material criticality is expressed by the three dimensions of supply risk, environmental implications, and vulnerability [13]. This article, however, neglects the dimension of vulnerability to supply restrictions. This is done in order to prevent double accounting of certain aspects. The substitutability as one of three criteria for assessing the vulnerability to supply restrictions is analyzed in detail in the subsequent steps. The inclusion of the dimension of vulnerability to supply restrictions would result 
in a circular reference between the evaluation of substitutability, which is based on the preceding assessment of material criticality (compare Section 2.2). The presented approach adopts the so-called "company-oriented model" developed by Kolotzek et al., which can be adapted to a product or technology level. The underlying three dimensions are supply risk, environmental impact, and social implications of raw material supply [14]. Incorporating the social aspect represents a significant added value to classic approaches to raw material criticality assessment. This is due to the fact that corporate social responsibility is expected both from customers as well as public authorities. The respective applied set of indicators provides a comprehensive overview of potential social problems in the upstream supply chain. The considered indicators for each dimension are documented in Table 1. For a short description of each utilized indicator, the reader is referred to the Supplementary Materials of [14]. The underlying base year of the obtained data for each indicator is 2019.

The selection of indicators for the supply risk dimension is equivalent to the eight most frequently applied indicators in related studies [37]. Thereby, the original indicator "country risk" is translated into the category "political risk", which is comprised of three individual indicators ("policy perception", "political stability", and "regulation"). In addition, the original indicator "depletion time" [37] is split into two indicators: "static reach of reserves" and "static reach of resources".

In turn, the dimension "environmental impact" is based on the methodology by Graedel et al., who apply the two LCIA endpoint categories "human health" and "ecosystem quality" by allocating various midpoint indicators (see Table 1) [13]. The "hierarchist" perspective of ReCiPe 2008 is chosen as the underlying LCIA method [38]. As ReCiPe already includes a weighting to transform mid- to endpoint indicators, the definition of an individual weighting for the present work is neglected.

The dimension "social implications" is defined by a selection of indicators based on the "research field of social life cycle assessments" [14]. Standardization and weighting of individual indicators for each dimension are adopted from Kolotzek et al., who applied an analytical hierarchy process (AHP) for the respective determination. Each indicator is normalized on a scale from 0 to 100, where zero equals the best and 100 the worst performance. For detailed information concerning the selection process of dimensions, indicators, and further methodological aspects, the reader is referred to the work of Kolotzek et al. [14]. In accordance with other recent studies [22,30], the presented work does not define criticality thresholds, since criticality itself generally represents a subjective concept that is largely based on the respective perception of stakeholders. However, the comparison between the single raw materials and cathode chemistries allows for classification in terms of "less and more critical". The circular form of visual depiction of the results of the raw material assessment (adapted from Kolotzek et al. [14]) allows for an indicator-specific interpretation and analysis (compare Section 3.1). Hence, potential problems in the supply chain of the evaluated raw materials can be identified, and approaches to improvement can be derived for further analyses. 
Table 1. Applied indicators for criticality assessment. The selection and weighting are based on [5], and the origin of data is stated in the column "reference".

\begin{tabular}{|c|c|c|c|c|c|}
\hline Dimension & \multicolumn{2}{|l|}{ Category } & Indicator & Abbreviation & Reference \\
\hline \multirow{11}{*}{ Supply Risk } & \multirow{2}{*}{\multicolumn{2}{|c|}{ Concentration Risk }} & Company Concentration & CompC & [24] \\
\hline & & & Country Concentration & CountC & [39] \\
\hline & \multirow{3}{*}{\multicolumn{2}{|c|}{ Political Risk }} & Policy Perception Index & PPI & {$[40]$} \\
\hline & & & $\begin{array}{l}\text { WGI: Political Stability and Absence of } \\
\text { Violence/Terrorism }\end{array}$ & WGI-PV & {$[41]$} \\
\hline & & & $\begin{array}{l}\text { Human Development Index: } \\
\text { Regulation }\end{array}$ & HDI & [42] \\
\hline & \multirow{3}{*}{\multicolumn{2}{|c|}{ Risk of Demand Increase }} & Companion Metal Fraction & CMF & [43] \\
\hline & & & Future Technology Demand & FTD & {$[44]$} \\
\hline & & & Substitutability (raw material) & Subs & [45] \\
\hline & \multirow{3}{*}{\multicolumn{2}{|c|}{ Risk of Supply Reduction }} & Recycling Rate & RR & [46] \\
\hline & & & Static Reach Reserves & SRRV & [24] \\
\hline & & & Static Reach Resources & SRRC & [24] \\
\hline \multirow{23}{*}{$\begin{array}{l}\text { Environmental } \\
\text { Impact }\end{array}$} & \multirow{9}{*}{\multicolumn{2}{|c|}{ Ecosystem Quality }} & Agricultural Land Occupation & ALO & [47] \\
\hline & & & Climate Change, Ecosystem & CCE & [47] \\
\hline & & & Freshwater Ecotoxicity & FEuc & [47] \\
\hline & & & Freshwater Eutrophication & FEut & [47] \\
\hline & & & Marine Ecotoxicity & MEct & [47] \\
\hline & & & Natural Land Transformation & NLT & [47] \\
\hline & & & Terrestrial Acidification & Tacd & [47] \\
\hline & & & Terrestrial Ecotoxicity & Tect & [47] \\
\hline & & & Urban Land Occupation & ULO & [47] \\
\hline & \multirow{6}{*}{\multicolumn{2}{|c|}{ Human Health }} & Climate Change, Human Health & $\mathrm{CCHH}$ & [47] \\
\hline & & & Human Toxicity & HAT & [47] \\
\hline & & & Ionising Radiation & IR & [47] \\
\hline & & & Ozone Depletion & OD & [47] \\
\hline & & & Particulate Matter Formation & PMF & [47] \\
\hline & & & Photochemical Oxidant Formation & POF & [47] \\
\hline & \multirow{8}{*}{$\begin{array}{l}\text { Local } \\
\text { Community }\end{array}$} & \multirow{2}{*}{$\begin{array}{l}\text { Access to Immaterial } \\
\text { Resources }\end{array}$} & WGI: Voice and Accountability & \multirow[b]{2}{*}{ AIR } & [48] \\
\hline & & & $\begin{array}{l}\text { Global Competitiveness Report: FDI } \\
\text { and technology transfer }\end{array}$ & & [49] \\
\hline & & $\begin{array}{l}\text { Access to Material } \\
\text { Resources }\end{array}$ & $\begin{array}{l}\text { Environmental Performance Index: } \\
\text { Water and Sanitation }\end{array}$ & EPI-WS & {$[50]$} \\
\hline & & \multirow{2}{*}{$\begin{array}{l}\text { Community } \\
\text { Engagement }\end{array}$} & GCR: Public Trust of Politicians & \multirow[b]{2}{*}{$\mathrm{CE}$} & [49] \\
\hline & & & $\begin{array}{l}\text { GCR: Transparency of Government } \\
\text { Policymaking }\end{array}$ & & [49] \\
\hline & & Cultural Heritage & Fragile State Index: Group Grievance & FSI-GG & {$[51]$} \\
\hline & & $\begin{array}{l}\text { Delocalization and } \\
\text { Migration }\end{array}$ & Fragile State Index: Refugees and IDPs & FSI-R & [51] \\
\hline & & Local Employment & Risk of Unemployment & LE & [52] \\
\hline
\end{tabular}


Table 1. Cont.

\begin{tabular}{|c|c|c|c|c|c|}
\hline Dimension & Category & & Indicator & Abbreviation & Reference \\
\hline \multirow{17}{*}{$\begin{array}{l}\text { Social } \\
\text { Implications }\end{array}$} & & \multirow{2}{*}{$\begin{array}{l}\text { Respect of } \\
\text { Indigenous Rights }\end{array}$} & $\begin{array}{l}\text { Risk That a Country Does not Provide } \\
\text { Laws to Protect Indigenous People }\end{array}$ & \multirow{2}{*}{ RIR } & \multirow{2}{*}{ [52] } \\
\hline & & & $\begin{array}{l}\text { Risk that Indigenous People are } \\
\text { Negatively Impacted }\end{array}$ & & \\
\hline & & $\begin{array}{l}\text { Safe and Healthy } \\
\text { Living Conditions }\end{array}$ & WHO: Age-standardized DALY rates & DALY & [53] \\
\hline & & \multirow{2}{*}{$\begin{array}{l}\text { Secure Living } \\
\text { Conditions }\end{array}$} & GCR: Security of Public Institutions & \multirow{2}{*}{ SLC } & [49] \\
\hline & & & GCR: Reliability of Police Services & & [49] \\
\hline & \multirow[b]{2}{*}{ Society } & Corruption & WGI: Control of Corruption & WGI-CC & [48] \\
\hline & & $\begin{array}{l}\text { Prevention and } \\
\text { Mitigation of Armed } \\
\text { Conflicts }\end{array}$ & HIIK Conflict Barometer & HIIK & {$[54]$} \\
\hline & \multirow{10}{*}{ Worker } & Child Labor & Risk of Child Labor & $\mathrm{CL}$ & [52] \\
\hline & & $\begin{array}{l}\text { Equal Opportuni- } \\
\text { ties/Discrimination }\end{array}$ & Gender Inequality Index & GII & [55] \\
\hline & & Fair Salary & $\begin{array}{l}\text { Risk of Average Wage Being Lower } \\
\text { Than Non-Poverty Guideline }\end{array}$ & FS & [52] \\
\hline & & Forced Labor & Risk of Forced Labor & FL & [52] \\
\hline & & \multirow{3}{*}{$\begin{array}{l}\text { Freedom of } \\
\text { Association and } \\
\text { Bargaining }\end{array}$} & $\begin{array}{l}\text { Risk of Not to Enforce the Right to } \\
\text { Strike }\end{array}$ & \multirow{3}{*}{ FA\&B } & \\
\hline & & & $\begin{array}{l}\text { Risk of Not to Enforce Freedom of } \\
\text { Association Rights }\end{array}$ & & [52] \\
\hline & & & $\begin{array}{l}\text { Risk of Not to Enforce Collective } \\
\text { Bargaining Rights }\end{array}$ & & \\
\hline & & \multirow{2}{*}{ Health and Safety } & Risk of Non-Fatal Injuries & \multirow{2}{*}{$H \& S$} & \multirow{2}{*}{ [52] } \\
\hline & & & Risk of Fatal Injuries & & \\
\hline & & Working Hours & Risk of Excessive Working Time & WH & [52] \\
\hline
\end{tabular}

The results on the elemental level (supply risk, environmental impact, social implications) are aggregated to the cathode-specific technology level. This is done by weighing the obtained values by mass shares of the respective raw material (or precursor material) within the considered cathode chemistries. This approach to calculating the criticality of material compounds or products is accepted in the scientific community [30-32]. The material compositions of the individual cathode chemistries can be obtained from Table 2. Thereby, lithium and manganese are applied as different derivates for some cathode chemistries. While lithium carbonate is used for NMC 111, NMC 532, NMC 622, LMO, and LCO [56,57], lithium hydroxide is required for the nickel-rich cathode NMC 811, LFP, and the NCA technologies [57-59]. The NMC-active material is comprised of manganese sulfate [57], while for LMO manganese dioxide is applied [60]. The respective information is involved for the environmental dimension. The indicators of the considered LCIA endpoint categories are assessed in both a raw-material-specific and derivate-specific manner. As no dataset exists for cobalt sulfate hexahydrate in the ecoinvent database [47], a mixed calculation from sulfuric acid and cobalt based on stoichiometric calculations is conducted.

\subsection{Evaluation of the Substitutability of LIB Cathode Chemistries}

The applied methodology for evaluating the substitutability of cathode chemistries is partially based on the approach to vulnerability assessment by Graedel et al. [13]. The respective components and context are illustrated in Figure 2. The substitutability is 
calculated by considering three categories (highlighted in cyan: the performance, the criticality, and the price of the substitute), which in turn are comprised of various indicators (highlighted in dark grey for the performance of the substitute, in green for the criticality of the substitute, and in blue for the price of the substitute). Potential substitutes in this regard are the mentioned cathode chemistries (compare Table 2). The weightings of the individual categories and indicators are based on an expert survey (cyan, green, and blue) or available assessments from the literature (dark grey). The respective approach and results are described at the end of this paragraph. The category "criticality of the substitute" is based on the results described in Section 2.1. The other two categories are described in detail in the following. The levels and categories that are highlighted in light grey are part of the approach to assessing the vulnerability but are neglected in the presented approach to assessing the substitutability of LIB cathode chemistries.

Table 2. Material shares of evaluated cathode chemistries.

\begin{tabular}{|c|c|c|c|c|c|c|c|c|c|c|}
\hline & $\mathrm{Li}_{2} \mathrm{CO}_{3}$ & $\mathrm{LiOH}$ & $\mathrm{NiSO}_{4}$ & $\mathrm{MnSO}_{4}$ & $\mathrm{MnO}_{2}$ & $\mathrm{CoSO}_{4}$ & $\mathrm{Al}_{2}\left(\mathrm{SO}_{4}\right)_{3}$ & $\mathrm{FeSO}_{4}$ & $\mathrm{H}_{3} \mathrm{PO}_{4}$ & Reference \\
\hline $\begin{array}{l}\text { NMC } \\
111\end{array}$ & 0.106 & & 0.298 & 0.298 & & 0.298 & & & & [8] \\
\hline $\begin{array}{l}\text { NMC } \\
532\end{array}$ & 0.106 & & 0.447 & 0.268 & & 0.179 & & & & [8] \\
\hline $\begin{array}{l}\text { NMC } \\
622\end{array}$ & 0.106 & & 0.536 & 0.179 & & 0.179 & & & & [8] \\
\hline $\begin{array}{l}\text { NMC } \\
811\end{array}$ & & 0.106 & 0.716 & 0.089 & & 0.089 & & & & [8] \\
\hline NCA $3 \%$ & & 0.106 & 0.824 & & & 0.045 & 0.025 & & & [8] \\
\hline NCA 9\% & & 0.106 & 0.734 & & & 0.14 & 0.02 & & & [8] \\
\hline LMO & 0.06 & & & & 0.94 & & & & & [8] \\
\hline LFP & & 0.04 & & & & & & 0.36 & 0.6 & [8] \\
\hline LCO & 0.11 & & & & & 0.89 & & & & [61] \\
\hline
\end{tabular}

The category "performance of the substitute" is assessed by taking five indicators into account. The selection of these indicators is based on a comparison and linkage of the results of two scientific articles [36,62]. Zubi et al. evaluated the characteristics of various LIB cathode chemistries (LCO, LMO, LFP, NCA, and NMC) based on eight indicators [62]. In order to connect their chemistry-specific results to application-specific requirements for LIBs, the eight indicators from Zubi et al. are matched with the nine indicators applied by Full et al. [36]. In the course of their evaluation of different LIB cell formats, they assessed the importance of various technical criteria for the main applications of LIBs (traction batteries, stationary energy storage systems, consumer electronics, power/garden tools, and domestic appliances) [36]. The comparison of these technical criteria can be obtained from Table 3. The five adopted indicators enable the evaluation of the performance of cathode chemistries for the considered applications. The remaining indicators are either neglected due to consideration in other dimensions or the non-availability of an appropriate match (compare Table 3). 


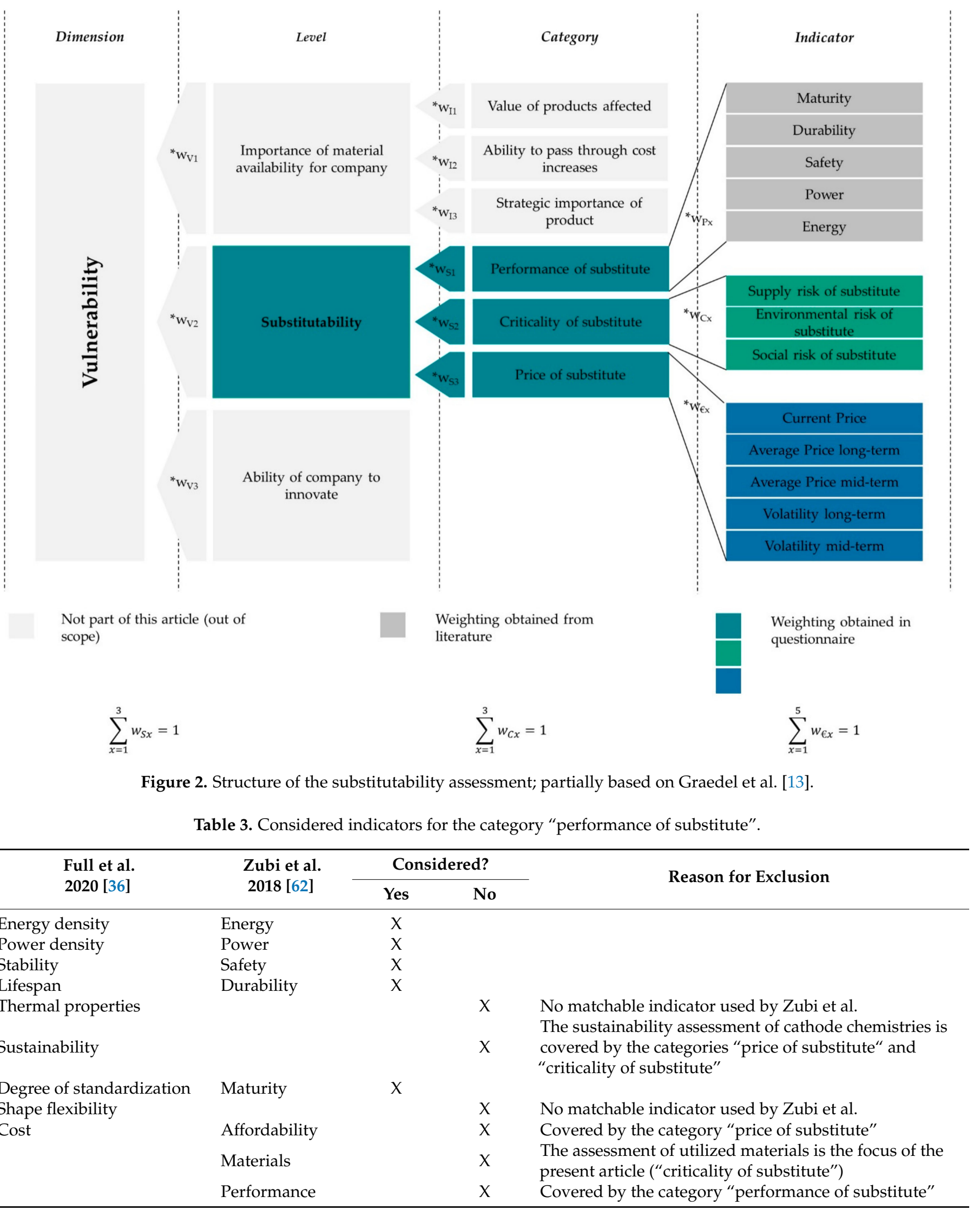

As Zubi et al. assess NMC and NCA batteries and do not further define the particular material composition (e.g., share of nickel, manganese, and cobalt), the supplied assess- 
ments are interpreted as averages for NMC 111-811 and NCA 3-9\%. Consequently, the scoring published by Zubi et al. is extended to represent existing variances in performance between the different material shares in similar families of cathode chemistries. Hence, nickel-rich NMC cathode chemistries (NMC 622 and 811) are assessed with lower maturity [63], lower durability [64], lower safety [9,65], and higher energy density $[9,66]$ than the previous generations (NMC 111 and 532). Similar to NMC cathodes, the maturity of low-cobalt NCA cathodes (NCA 3\%) is defined to be lower than that of high-cobalt NCA cathodes (NCA 9\%). Furthermore, the durability and safety are assessed to be lower, while the energy density is assessed to become higher with decreasing cobalt share [67]. The underlying scores are listed in the Supplementary Materials. The obtained values for the individual indicators concerning the performance of the cathode chemistries are multiplied by the respective importance for the considered applications. The assessment of importance obtained from Full et al. is transformed to a scale that ranges from 0 (not important) to 1 (very important) and the sum is normalized to 1 . Consequently, the importance is used for indicator weighting. The sum of the weighted indicator values per application results in the desired application-specific performance rating of LIB cathode chemistries. The respective values can be found in the Supplementary Materials.

Identifying costs of raw materials represents a difficult task, as the raw material market is highly volatile and depends on numerous impact factors. In order to integrate the dimension "cost of the substitute", five indicators are introduced. These are expected to cover the current price of the substitute as well as the potential future development based on historical data. Historical data are provided on a medium (2000-2015) and long-term timescale (1990-2015) for the average price and the price volatility of the raw materials. Data for the introduced indicators are obtained on a raw material level, not for specific cathode materials, as the respective information is not publicly available. This applies especially to the indicators that are based on historic data. For the same reason, a differentiation between derivates of the utilized materials (e.g., lithium hydroxide vs. lithium carbonate) is not taken into consideration. Once more, the aggregation to the product level (cathode chemistry) is based on the material shares (compare Table 2). The current price of the commodities refers to the average price in 2019 [68]. The only exemption is iron, which is used in LFP cathodes. The price of iron is neither mentioned in the "DERA Preismonitor" nor in the "mineral commodity summaries" of the USGS [24,68]. The most current information concerning the price of iron in the literature was found for 2018 [69]. The historical price averages refer to prices in the United States [70]. The historical volatility is equated with the standard deviation of the logarithmic price changes from one year to another in the considered timespans [71]. The historical raw material prices in the United States were chosen as the underlying data [70]. The Supplementary Materials of the present article provides more detailed information concerning the utilized datasets.

For the final assessment (see Section 3.3), each indicator from each dimension is normalized on a scale that ranges from 0 to 1 , where 0 is defined as the potential optimal value per indicator (e.g., the optimal value of the indicator "current price" in the dimension "price of the substitute" equals 0 US \$). The value 1 , as the upper end of the scale, is equated with the worst value that is achieved by one of the considered cathode chemistries (e.g., LCO attains the highest current material costs; hence, the 30,295 US \$/t are defined as 1 on the introduced scaling). Consequently, cathode chemistries that attain the lowest score are qualified the most as potential substitutes in the respective field of application.

The weightings were obtained from an analytical hierarchy process (AHP). The respective methodology is based on Saaty et al. [72]. The weightings of the indicators of the categories "criticality of the substitute" $\left(\mathrm{w}_{\mathrm{cx}}\right)$ and "price of the substitute" $\left(\mathrm{w}_{\epsilon_{\mathrm{X}}}\right)$ as well as of the three categories within the level "substitutability" $\left(w_{\mathrm{sx}}\right)$ were obtained by pairwise comparisons using a structured questionnaire. A sample of the utilized questionnaire can be found in the Supplementary Materials. As the importance of the individual indicators for the considered fields of application was obtained from Full et al., the respective weighting of the category "performance of substitute" was not requested in the 
questionnaire [36]. The sum of the individual weightings for the categories as well as for the level "substitutability" equals 1 (or 100\%), respectively. Figure 2 visualizes the content of the questionnaire. Experts from battery-related research institutions and companies were asked to give their opinion about the importance of the mentioned indicators and categories from the viewpoint of a producer/distributor of LIBs. Information concerning the surveyed experts can be found in the Supplementary Materials. The final weightings were obtained by calculating the average of the valid expert opinions. The threshold value for the consistency check of the expert's answers, according to Meixner and Haas, was defined as 0.2 [73]. Only one returned questionnaire had to be neglected in the calculation of the average weightings due to the exceedance of the consistency value. The obtained weightings can be found in Table 4 . The weightings for the indicators of the performance category $\left(\mathrm{w}_{\mathrm{px}}\right)$, obtained from Full et al. [36], can be found in the Supplementary Materials.

Table 4. Weightings of categories / indicators obtained from the AHP process.

\begin{tabular}{llcc}
\hline \multicolumn{1}{c}{ Level/Category } & \multicolumn{1}{c}{ Category/Indicator } & Abbreviation & Weighting \\
\hline \multirow{3}{*}{ Substitutability } & Performance of the substitute & $\mathrm{w}_{\mathrm{s} 1}$ & 0.410 \\
& Criticality of the substitute & $\mathrm{w}_{\mathrm{s} 2}$ & 0.269 \\
& Price of the substitute & $\mathrm{w}_{\mathrm{s} 3}$ & 0.321 \\
& $\sum$ & & 1 \\
\hline & Supply risk of the substitute & $\mathrm{w}_{\mathrm{c} 1}$ & 0.520 \\
Criticality of substitute & Environmental risk of the substitute & $\mathrm{w}_{\mathrm{c} 2}$ & 0.244 \\
& Social risk of the substitute & $\mathrm{w}_{\mathrm{c} 3}$ & 0.236 \\
& $\sum$ & & 1 \\
\hline & Current price of the substitute & $\mathrm{w}_{€ 1}$ & 0.161 \\
Price of substitute & Average price long-term of the substitute & $\mathrm{w}_{€ 2}$ & 0.273 \\
& Average price mid-term of the substitute & $\mathrm{w}_{€ 3}$ & 0.276 \\
& Volatility long-term of the substitute & $\mathrm{w}_{€ 4}$ & 0.134 \\
& Volatility mid-term of the substitute & $\mathrm{w}_{€ 5}$ & 0.157 \\
& $\sum$ & & 1 \\
\hline
\end{tabular}

\section{Results}

The results are organized into three subsections. The first summarizes the findings from the criticality analysis on the raw material level as well as the aggregated perspective on the cathode-chemistry level. The second subsection describes the results concerning the price and performance category of the considered cathode chemistries. Finally, all individual results are merged in the last subsection, where the substitutability of the mentioned cathode chemistries for the considered fields of application of LIBs is described.

\subsection{Criticality of Cathode Materials for Lithium-Ion Batteries}

The criticality of raw materials is not aggregated to a single criticality value. The results are discussed on the indicator level to identify specific problems in the upstream supply chain. This shall create sensitization to potential difficulties in supply from a market and political perspective, but also under the circumstance of the expected transformation to stricter requirements concerning environmental and social standards from consumers as well as legislative entities. The depiction of raw material criticality is based on Kolotzek et al., who developed an expressive layout by using three superimposed circle diagrams [14]. The inner circle visualizes the accumulated results of the three dimensions. The middle circle is a little more specific in depicting the defined categories and the outer circle provides the most detailed information on the indicator level. The color-coded scale, as depicted in Figure 3, reaches from green (least critical $=$ transformed value of 0 per indicator) to red (most critical = transformed value of 100 per indicator).

The results for the individual material criticality assessments are illustrated in Figure 4. Compared with the other considered elements, cobalt is assessed with the highest supply risk, directly followed by lithium. This is in line with the results of other studies $[18,30,31]$. 
In turn, iron is scored with the least critical supply risk of the considered elements, followed by aluminum. This is the other way round in the assessment of Wentker et al. [31]. As the same indicators are selected, the variation should be considered in the light of the more upto-date data applied in this article (base year 2019). This results in less critical scores of iron for the indicators "company concentration", "country concentration", and "regulation".

Figure 3. Applied color-coded scale for raw material criticality.

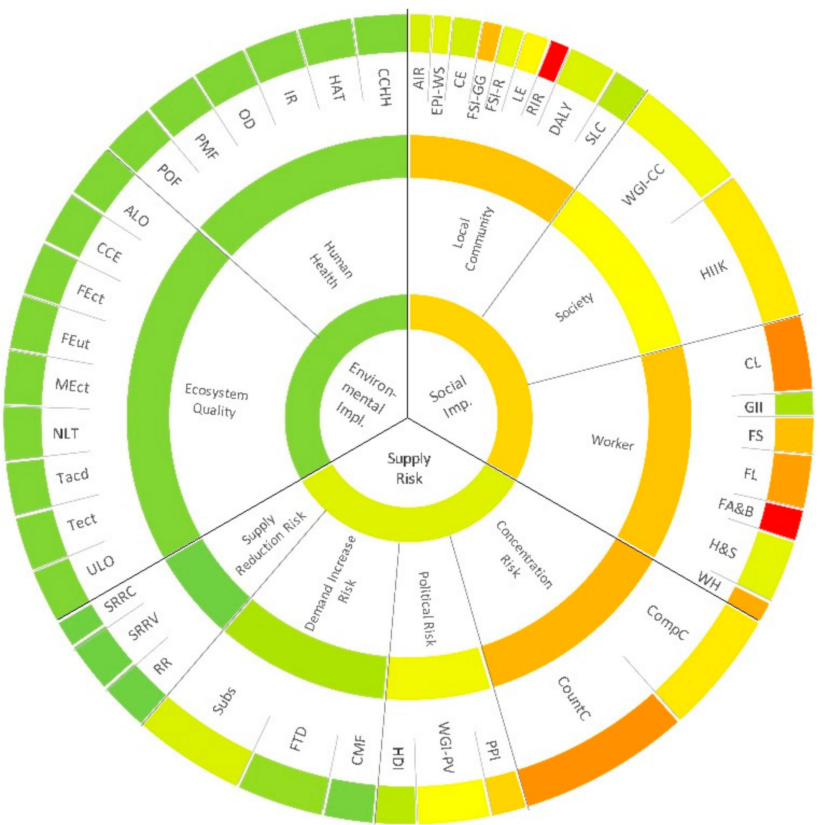

(a)

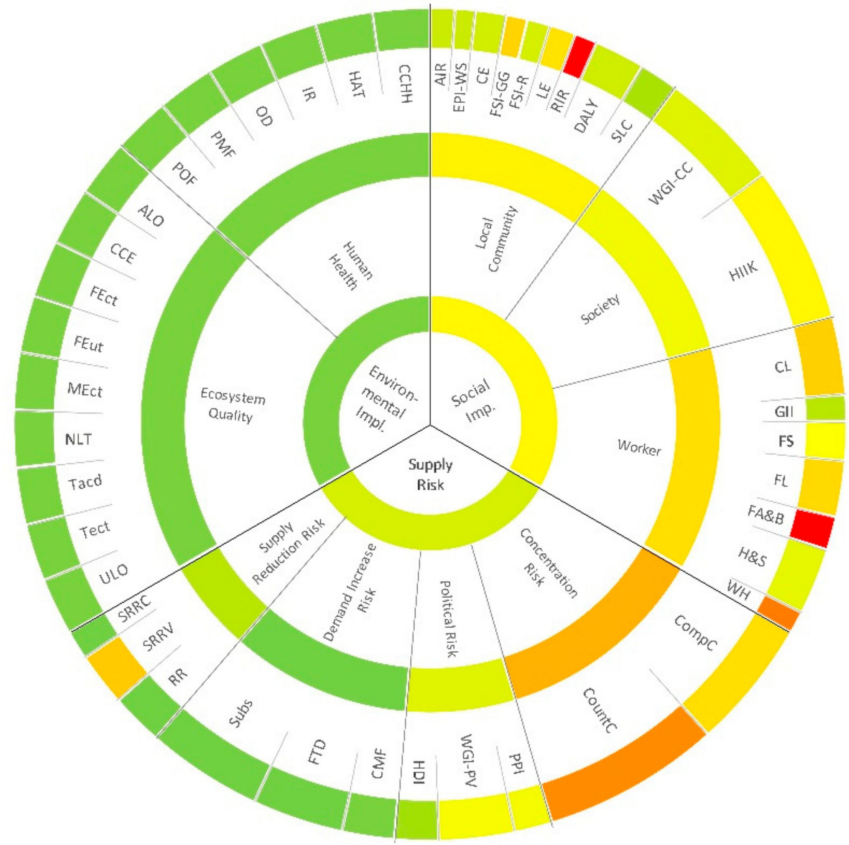

(c)

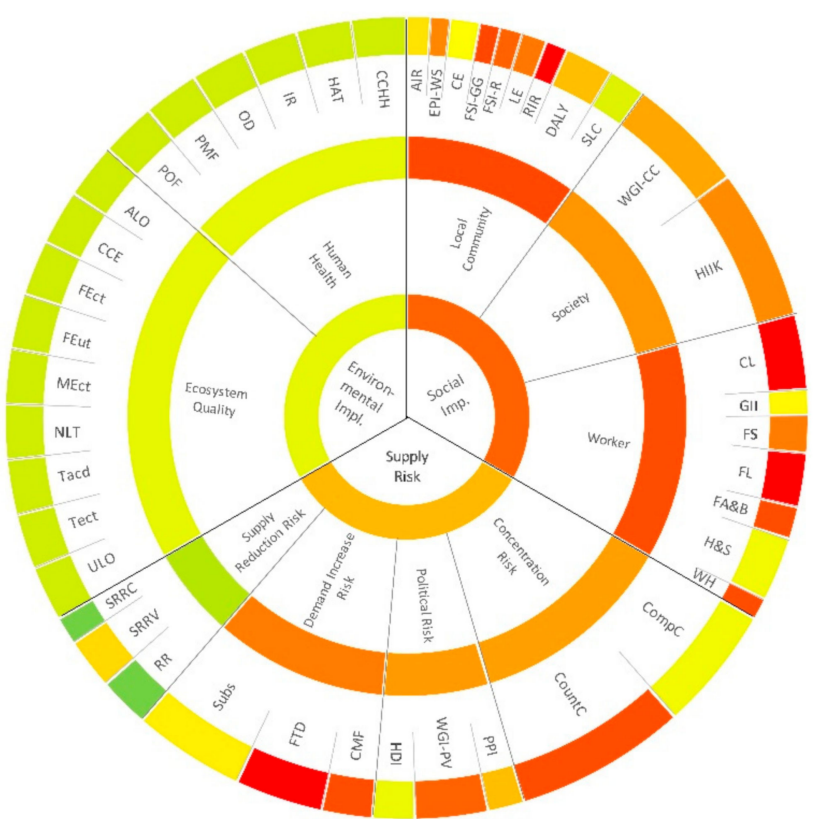

(b)

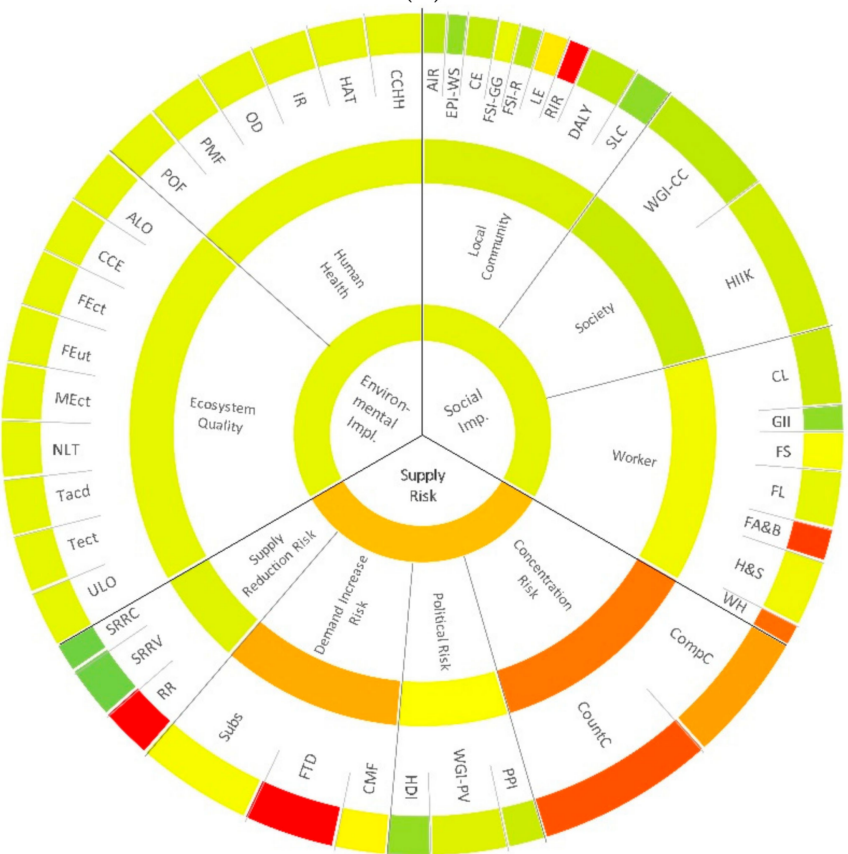

(d)

Figure 4. Cont. 


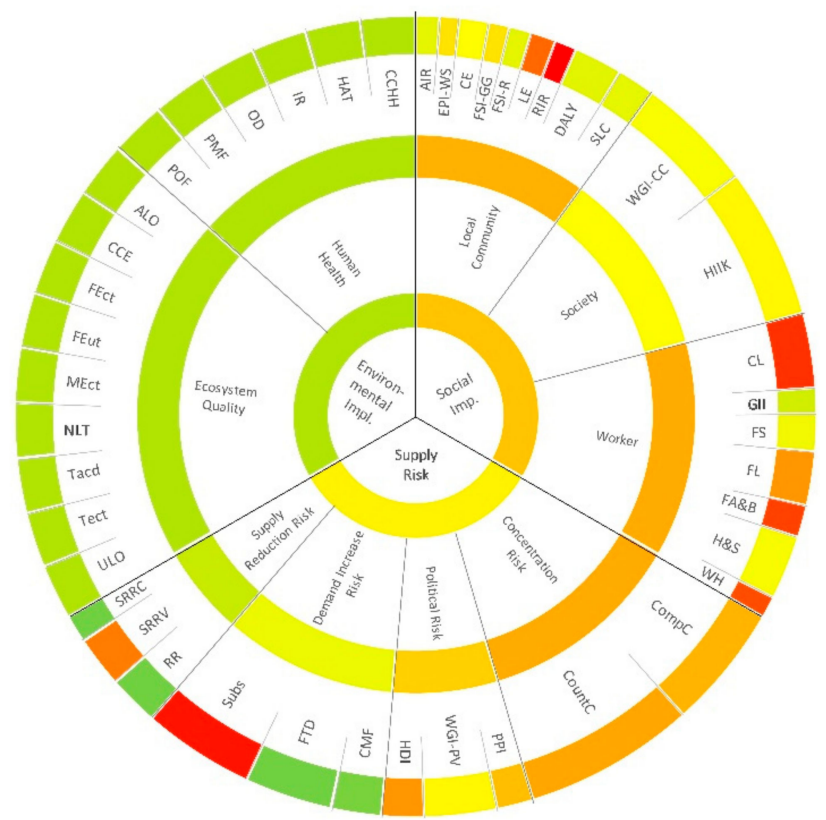

(e)

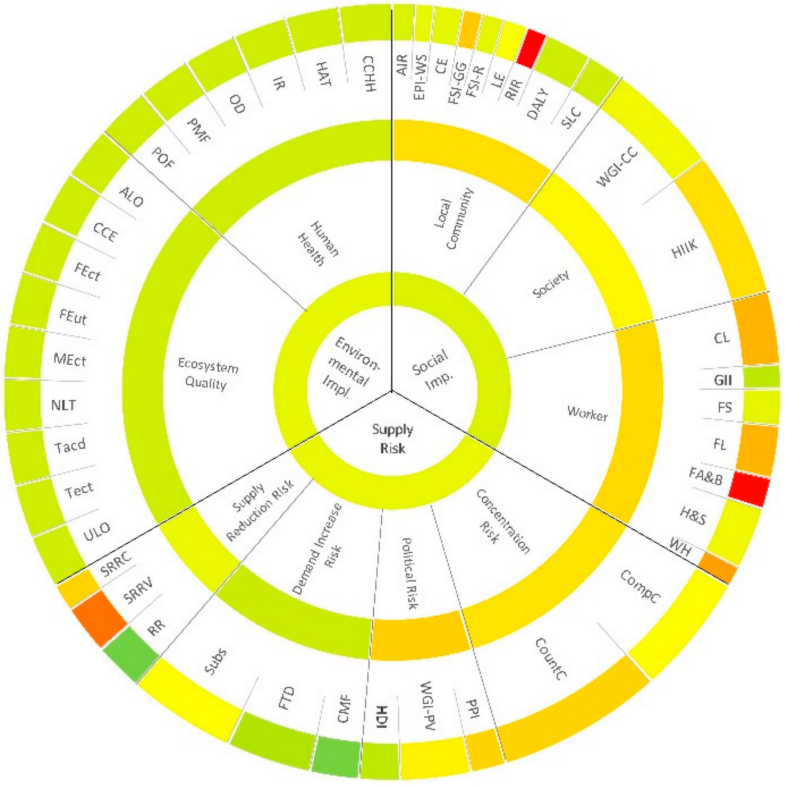

(f)

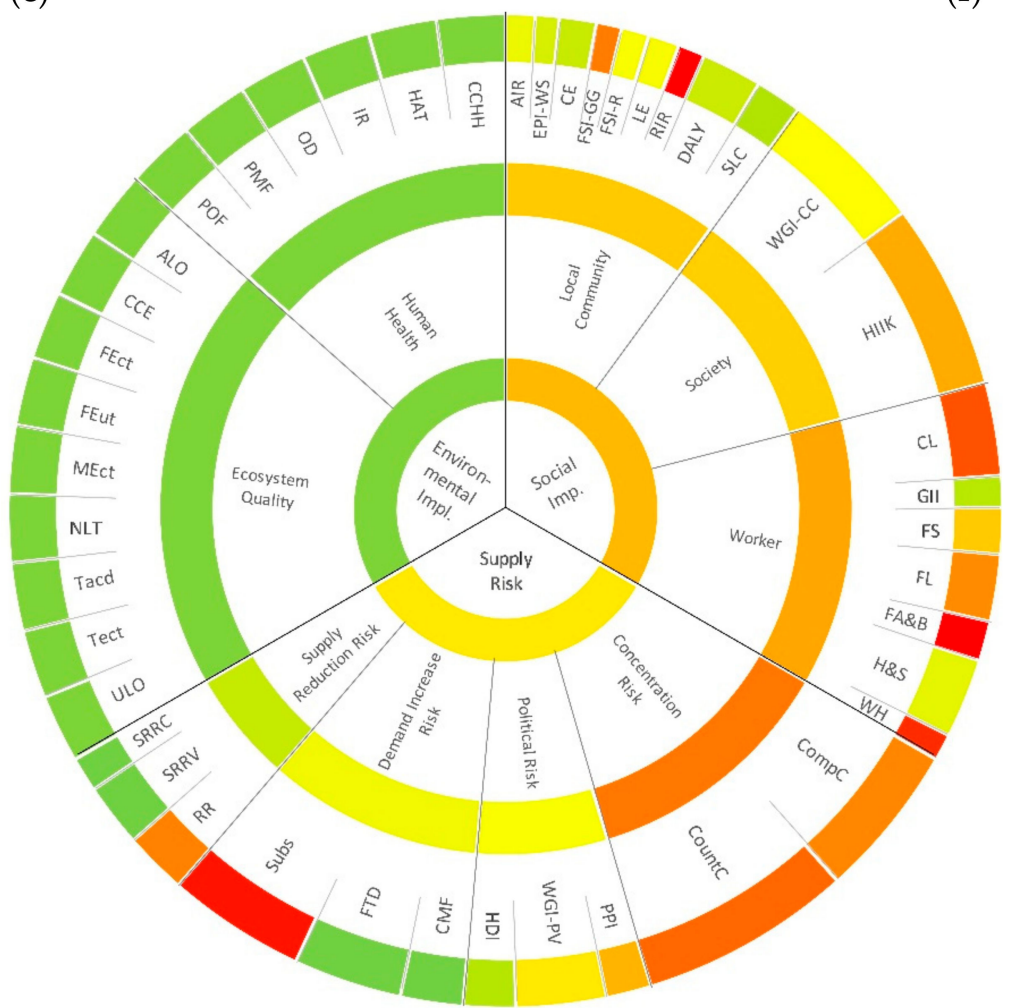

(g)

Figure 4. Results of the raw material criticality assessments for: (a) aluminum; (b) cobalt; (c) iron; (d) lithium; (e) manganese; (f) nickel; and (g) phosphorus.

The lowest ecological implications occur from the mining of iron, followed by phosphorus and aluminum. Manganese, nickel, and cobalt follow after a considerable gap. The supply of lithium is accompanied by the highest ecological implications by far. Wentker et al. come to the same conclusions concerning cobalt, nickel, and lithium. However, according to their assessment, manganese and nickel are scored with an even lower environmental impact than phosphorus and aluminum [31]. The environmental impacts published by Graedel et al. are nearly the same for $\mathrm{Co}, \mathrm{Mn}, \mathrm{Al}, \mathrm{Li}$, and Fe. Only nickel is assessed 
as a little more critical [18]. These differences suggest that the dimension of ecological implications is highly dependent on the reference year of the applied data.

Compared with the other assessed elements, aluminum trends towards a rather uncritical assessment. The noticeable concentration risk (particularly the country concentration) is based on the fact that more than half of the world's aluminum production takes place in Australia and China [24]. Political circumstances in China, Brazil, Guinea, and India are the central reasons for the rather critical overall rating of the "policy perception index" (PPI) and the political stability and absence of violence indicator (WGI-PV) [40,41]. The implications for the environment are assessed as low (the third-lowest score of the considered elements) [47]. In the social dimension, the Fragile State Index: Group Grievance (FSI-GG) is scored as rather critical-as are Child Labor (CL) and Forced Labor (FL). Generally, it has to be stated that, for all elements, the indicators Respect of Indigenous Rights (RIR) and Freedom of Association and Bargaining (FA\&B) are assessed as highly critical. Further research needs to analyze if this is a coincidence, or if the transformational rule obtained from Kolotzek et al. needs to be revised.

Cobalt mining is highly centralized. In 2019, around $65 \%$ of the world's production was mined in the Democratic Republic of Congo [24]. The Central African state is also the main reason for alarming political risks due to the critical ratings of the PPI, the WGI-PV, and the human development index (HDI) [40-42]. The supply risk is enhanced as cobalt is mainly extracted as a by-product metal of nickel and copper mining [43]. Furthermore, a significant increase in demand is expected for future technologies (mainly for LIBs) [44]. From the considered elements, the mining of cobalt is responsible for the second-highest environmental impact [47]. Concerning the social implications of cobalt mining, similar tendencies to the supply risk dimension can be observed. The strong concentration of mining operations in the Democratic Republic of Congo affects the social indicators negatively. Particularly highlighted in this regard are the scores for the FSI-GG and the Fragile State Index: Refugees and IDPs (FSI-R) [51]. Worth mentioning are also the rather critical assessments for the control of corruption indicator (WGI-CC), the HIIK conflict barometer (HIIK), and the water and sanitation indicator of the environmental performance index (EPI-WS) [48,50,54].

Except for the dimension of social implications (the second-lowest score after lithium), iron is assessed as the least critical of the considered elements. One of the aspects that increases the overall supply risk of the raw material is the high concentration of production. In 2019, more than half of the world's mining activity was located in Australia and Brazil. Taking China and India additionally into account, the production share of these four countries accounts for more than $80 \%$. While the static reach of resources can be regarded as uncritical, the static reach of reserves is advised to be monitored as it currently only accounts for approximately 60 years [24].

The high supply risk of lithium is only surpassed by that of cobalt. The concentration risk of lithium is extremely high, as, in $2019,60 \%$ of the world's lithium supply was produced in Australia (2019) [24]. However, it has to be stated that the political risk in the lithium-producing countries is rather low [40-42]. The future technology demand is scored with the highest possible value. This is mainly due to the expected increasing demand for LIBs [44]. Additionally, the recyclability of lithium is assessed as highly critical [46]. Nevertheless, it has to be stated that some processes exist that are capable of extracting derivates of lithium from end-of-life LIBs [74]. From a social point of view, lithium mining is rather uncritical compared with the other assessed elements.

Although the concentration risk of manganese is worth noting, it is low compared with the other considered elements (except for nickel) [24]. Manganese-producing countries are assessed with a medium political risk [40-42]. However, manganese is difficult to substitute on a material level [45]. Furthermore, the static reach of the identified reserves is comparatively low (44 years) [24]. In summary, this ranks manganese in fourth place (out of seven) concerning the supply risk dimension. The same ranking applies to the dimension of "environmental impact" [47]. Nearly all social indicators are assessed with a 
medium criticality. Thereby, the EPI-WS and the FSI-GG in particular increase the average value for the social implications dimension [50,51].

From the considered elements, the supply of nickel is the most diversified. However, significant mining activities in Colombia, Guatemala, and, most relevantly, China, Russia, Indonesia, and the Philippines (in ascending order by mined metric tons) impact the political risk negatively [40-42]. Worth mentioning is the short static reach of reserves (41 years), but even more the static reach of resources. A static reach of resources of approximately 60 years is by far the shortest of the considered elements (the second-shortest static reach of resources is that of cobalt with around 220 years) [24]. Although the color code suggests a rather uncritical environmental impact, that of nickel represents the thirdhighest score. Consequently, it is interpreted as worth mentioning and monitoring [47]. Similarly, for manganese, most of the social indicators are assessed with medium criticality. The deviations are the high scores for the indicators "cultural heritage" and "prevention and mitigation of armed conflicts" (both mainly caused by the respective situations in Brazil, Colombia, Guatemala, Indonesia, Russia, and the Philippines) [51,54].

Phosphorus is scored with the third-highest supply risk of the assessed elements. This is mainly due to the significant company and country concentration of phosphate mining activities [24], high risks concerning the policy potential and political stability in the respective countries [40,41], the non-substitutability in the main applications [45], and the low recycling rates [46]. The environmental impact of phosphorus supply is scored as very low (only undercut by iron) [47]. The social implications of phosphorus mining, in turn, are comparably high, which is mainly due to high scores for the FSI-GG, the HIIK, the WGI-CC, and the FSI-R $[48,51,54]$.

The results concerning the criticality of the individual elements were merged according to the approach described in Sections 2.1 and 2.2. By multiplying the scores in the three dimensions per element with the respective material shares in the cathode chemistries (compare Table 2), absolute values per dimension and cathode chemistry were obtained. Figure 5a illustrates the corresponding results. By combining the weighting obtained from the AHP process, the dimensions were summed to one weighted criticality value per cathode chemistry (compare Figure 5b).

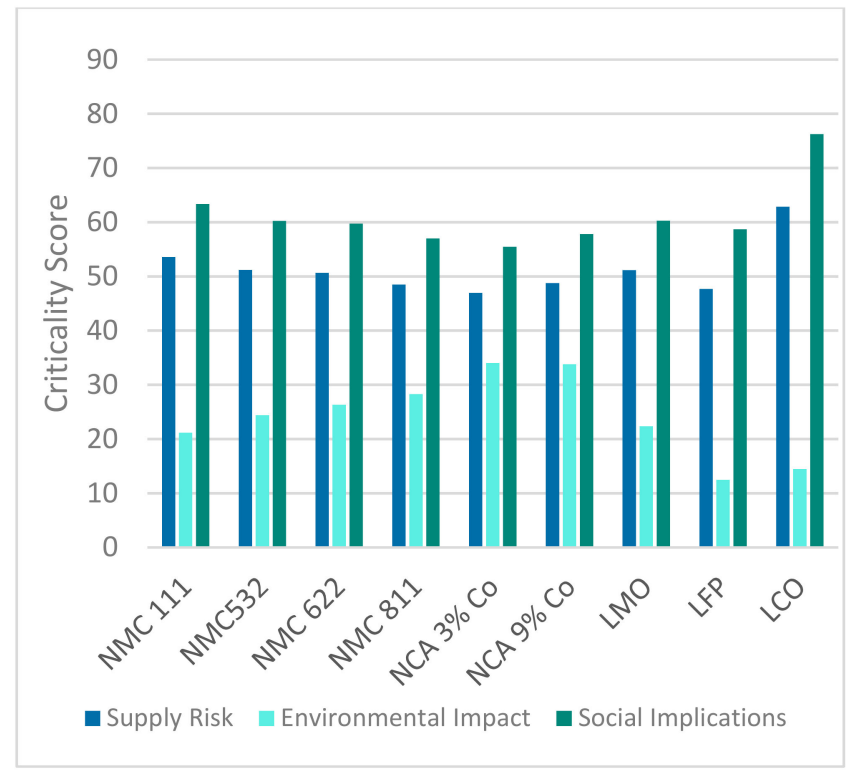

(a)

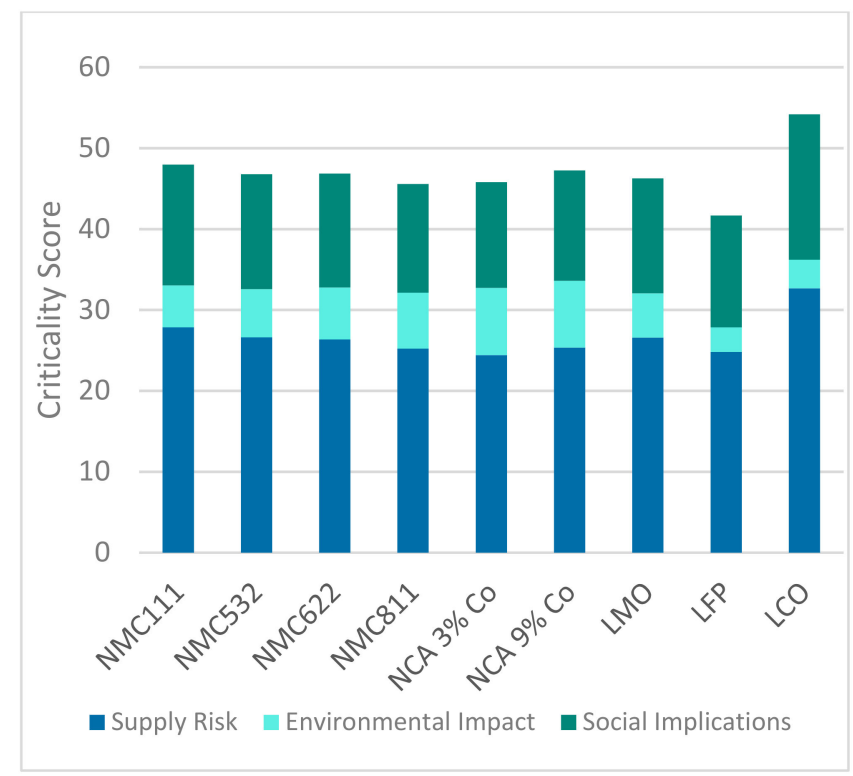

(b)

Figure 5. Criticality of LIB cathode chemistries: (a) absolute values of the three dimensions of criticality (supply risk, environmental impact, social implications); (b) weighted criticality value. 
It is noticeable that the supply risk and the social implications seem to be correlated, with the social implications being more critical for all cathode chemistries. This is due to the fact that some of the supply risk indicators as well as all of the social implications indicators are dependent on the mining countries. Hence, there seems to be a causal relation between political and social circumstances. The high cobalt contents of NMC 111 and LCO result in significant supply risks as well as social implications. It is interesting to see that LMO has a high supply risk even though it contains no cobalt. This results from the supply risk of manganese, which is rated between cobalt and nickel. The NCA cathodes with a low cobalt share (NCA 3\%) are scored with the lowest supply risk and social implications. For all of the considered elements, the environmental impact is assessed as rather low compared with the other two dimensions. Thereby, the NCA cathodes lead the order by far. Increasing the shares of nickel while decreasing the share of manganese from NMC 111 to NMC 811 results in higher environmental impacts. LFP obtains the lowest scores concerning environmental impact, which are due to the very low scores of phosphorus and iron in this dimension.

For the further analysis of substitutability, the normalized criticality per dimension and cathode chemistry is used. The normalization, which is described in Section 2.2, transforms the results on a scale from 0 (the best case) to 1 (defined as the maximum value one of the cathode chemistries achieves in the individual dimension). The respective values can be obtained from the Supplementary Materials.

\subsection{Performance and Price of the Considered Cathode Chemistries}

The performance of cathode chemistries is assessed on a scale from 0 to 2 (compare Section 2.2) [62]. The importance of the five analyzed indicators for the fields of application is based on the same scale [36]. However, as described in Section 2.2, for the purpose of normalization, the importance is transformed into a percentage scale (e.g., if all indicators are assessed with the highest importance of 2 , they are transformed to be equally important: $0.2 / 0.2 / 0.2 / 0.2 / 0.2)$. Consequently, the maximum performance score per field of application and cathode chemistry equals 2 . Figure 6 visualizes the results. It can be observed that, on average, the requirements for power- and garden tools are fulfilled the most with state-of-the-art cathode chemistries.

The LCO cathode chemistry is scored with the worst performance in every field of application. Even for consumer electronics, which is the main application for LCO LIBs, the preferred characteristics are not covered satisfactorily. The low-cobalt-containing NCA cathode chemistry follows with the second-worst rating. Between the other cathode chemistries, the one that is to be preferred varies depending on the field of application. The NMC 532 is top-rated in every field of application except for "stationary energy storage systems", which is dominated by NMC 111.

NMC cathodes are the technologies most favored for application in traction batteries. Following NMC 532, NMC 111, and NMC 811, LFP also achieves a high performance rating. $\mathrm{LCO}, \mathrm{NCA} 3 \%$, and $\mathrm{LMO}$ are not advised to be utilized for traction batteries based on the present assessment.

For stationary energy storage systems, NMC 111 and LFP are best suited. With a rating of 1.85 and 1.84, respectively, their performance score is nearly the same. Interesting to observe is the low performance rating of NMC 811, although it achieves mostly high scores for the other fields of application. LMO performs satisfactorily and nearly achieving the same performance rating as NMC 622.

The order of preference based on the performance rating is very similar for the remaining fields of application (consumer electronics, power-/garden tools, and domestic appliances). The second place varies between NMC 111 (power-/garden tools, domestic appliances) and NMC 811 (consumer electronics). LFP is also assessed with a high performance rating for all three fields of application. The sixth and seventh places alternate between cobalt-rich NCA (consumer electronics, domestic appliances) and LMO (power- 
and garden tools). Again, the transformed values (scale: 0-maximum value) were used for further analysis and can be found in the Supplementary Materials.

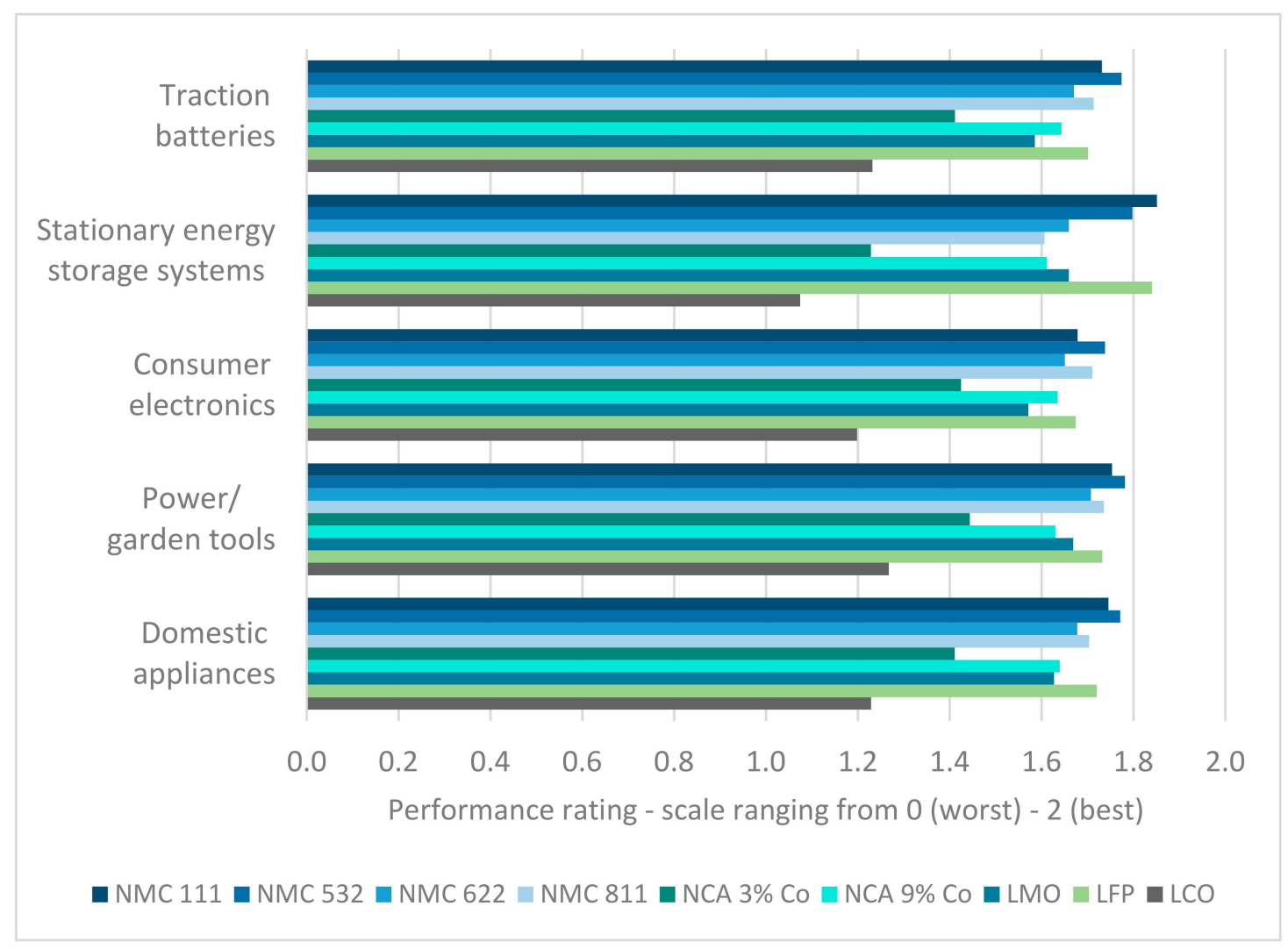

Figure 6. Performance of the considered cathode chemistries in different fields of application.

The price of the substitute is assessed by the use of five indicators (compare Section 2.2). Figure 7 illustrates the respective results for the nine considered cathode chemistries. The decrease in cobalt shares in cathodes results in significant price drops (on a raw material level). The price increase resulting from the evolution from NMC 532 to NMC 811 represents an intriguing finding. This is due to the fact that nickel is more expensive than manganese. Although the share of cobalt is decreased from $20 \%$ to $10 \%$, the accompanying monetary benefit cannot compensate for the additional costs originating from the increase in the nickel share from $50 \%$ to $80 \%$ at the cost of a decreasing manganese share. LCO is by far the most expensive cathode chemistry due to the significant amounts of cobalt the cathode is comprised of. The cobalt-rich NCA (NCA 9\%) and NMC (NMC 111) are the second and third most expensive cathode chemistries based on raw material prices. The derivates of NMC and NCA vary in price but mostly are on a similar level between 13,600 US\$ and 16,000 US\$ per ton of raw materials. As the identified costs for raw materials for the LFP cathode are extremely low, an additional approach was taken that is expected to be more realistic. This was done to allow for a discussion about the impact of the price dimension for the substitutability of cathode chemistries. According to the literature, LFP cathode material currently costs around 43\% of the price of NMC 811 cathode material [75]. Consequently, the price indicators visualized on the right-hand side of Figure 7 equal $43 \%$ of the identified NMC 811 prices on a raw material level, which is also depicted in Figure 7 (fourth from the left). It appears that the price indicators are consequently assessed as significantly higher than the original score of LFP (Figure 7-third from the right). Although it surpasses LMO, the adjusted price of LFP is still lower than that of the other cathode chemistries by far. Once again, all obtained values were transformed to the introduced scale from 0 to the maximum value (see Supplementary Materials). The 
resulting scores were weighted by the weightings obtained from the AHP and merged to an overall price score.

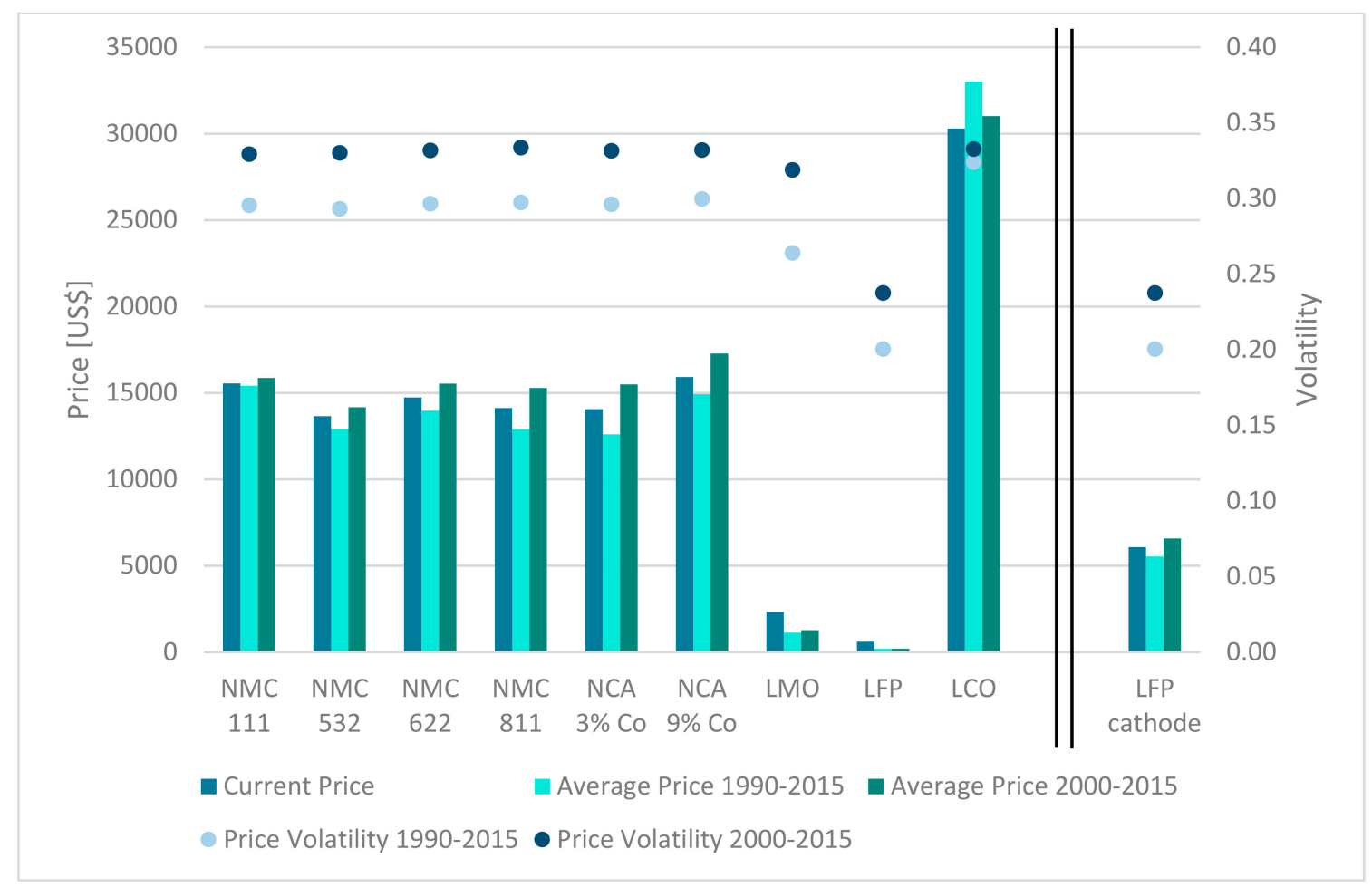

Figure 7. Price indicators for cathode chemistries.

\subsection{Substitutability of Cathode Chemistries}

The obtained scores for the criticality, performance, and price categories (compare Sections 3.1 and 3.2) are summed to a substitutability value per cathode chemistry and field of application by deploying the respective weightings from the AHP. Consequently, the substitutability score is in the range from 0 to 1 , where 0 equals the highest potential for substitution and 1 equals the lowest. The results can be obtained from Figure 8. Generally, the impact of the criticality category is rather small, as the respective variations in criticality scores are minimal and the consulted experts assessed the importance of the category as low. Using the described transformation rules as well as the introduced weightings, noticeable differences can only be identified between high cobalt-containing cathode chemistries (LCO, NCA 9\%, NMC 111) and LFP.

In contrast, the price dimension has a significant impact on the overall substitutability score due to the large spreads of the individual raw materials (especially phosphorus/iron vs. cobalt/nickel) as well as a higher weighting than the criticality dimension.

The dimension of performance, which is attributed as the most important from the viewpoint of a producer/distributor of LIBs, consequently has substantial effects on the substitutability of cathode chemistries. Various chemistries are more or less on a similar level of substitutability when only taking the criticality and price dimensions into account. The decisive factor in these cases is the dimension of performance.

LFP achieves the lowest and thus best scores for every field of application. This is not even changed by taking the higher price of the cathode material into account as described in Section 3.2. The respective score of LFP with the adjusted price of the cathode material is depicted on the right-hand side of Figure 8a-e (labeled 'LFP cathode'). 


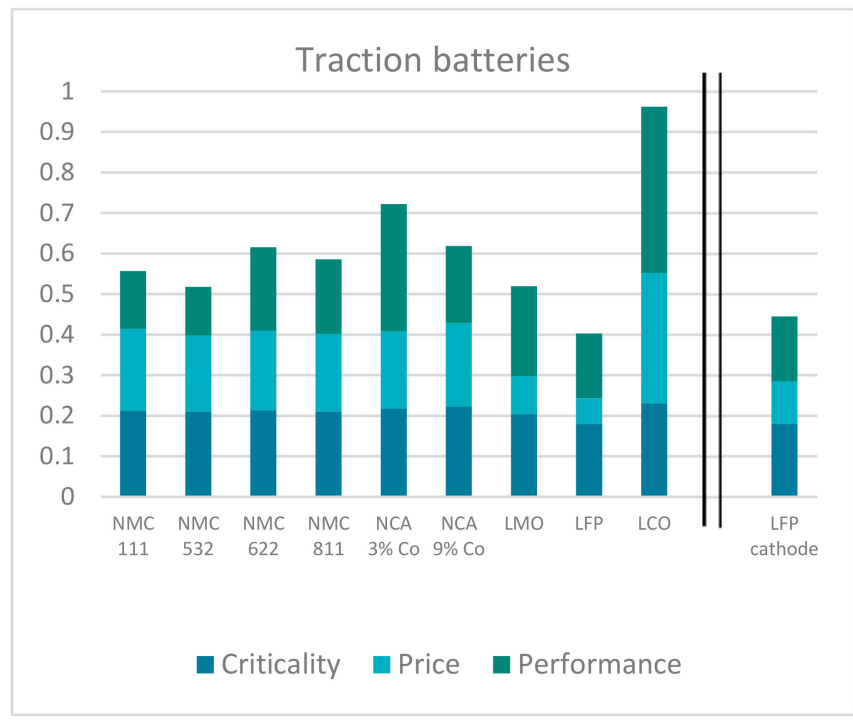

(a)

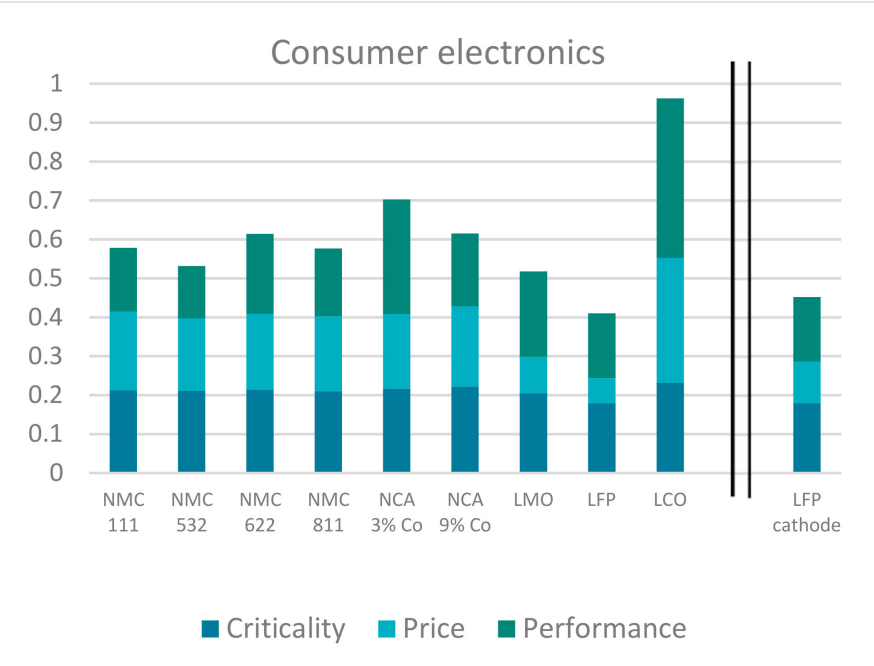

(c)

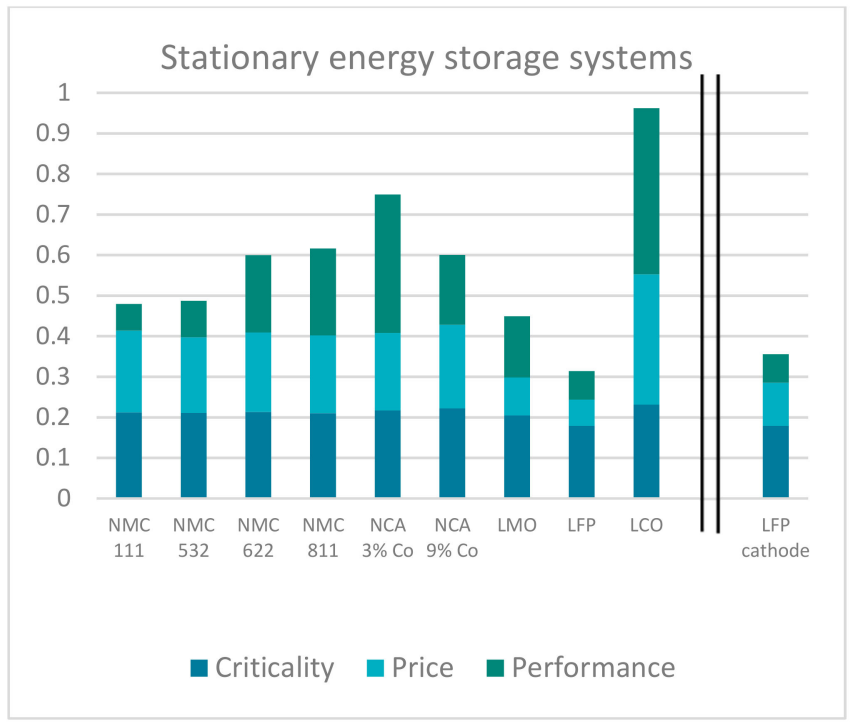

(b)

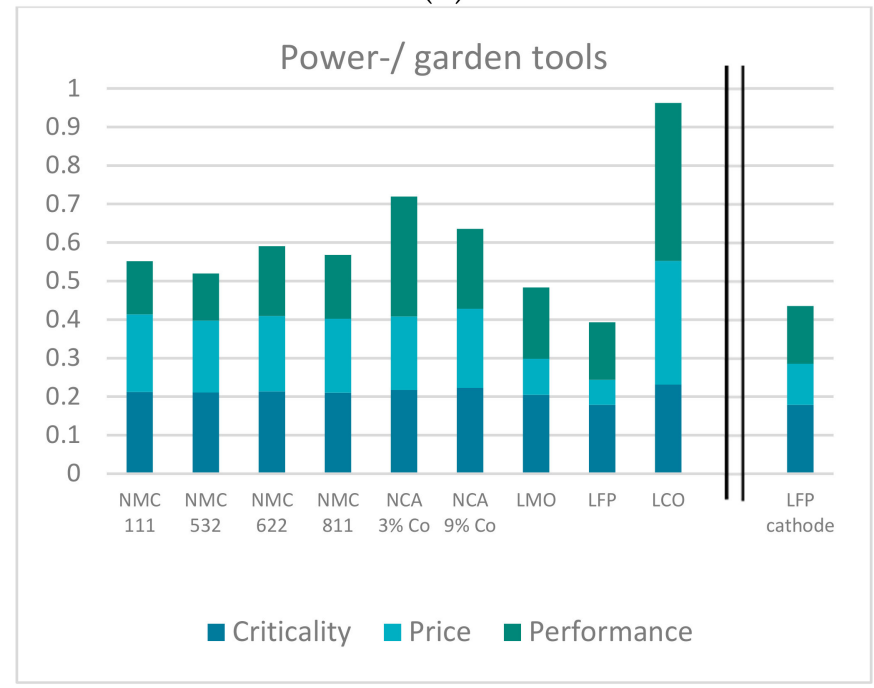

(d)

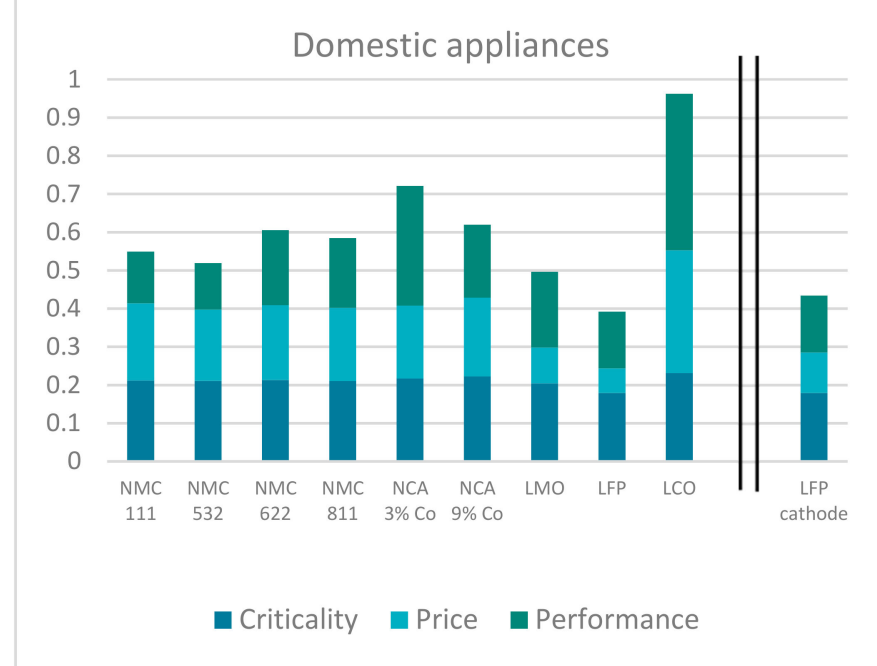

(e)

Figure 8. Results for the substitutability of cathode chemistries for the considered fields of application: (a) traction batteries; (b) stationary energy storage systems; (c) consumer electronics; (d) power-/garden tools; and (e) domestic appliances. 
In contrast, LCO is not suggested in any of the considered fields of application as a potential substitute. Its high cobalt content, while still achieving the worst scores in the performance dimension for every field of application, disqualifies LCO as a suitable cathode chemistry for LIBs.

According to the presented evaluation, the second-best option for traction batteries would be the NMC 532 cathode chemistry. Although performing nowhere near NMC, LMO achieves almost the same substitutability level as NMC 532. This is due to the significantly lower costs of the raw materials, mainly owing to the cobalt-free composition. By taking the weighting obtained from the expert interviews into account, NMC 111 is preferable for utilization in traction batteries although it has higher cobalt content compared with NMC 622 and 811. This is contrary to the current trend. Both NCA cathode chemistries achieve high and thus poor substitutability ratings, only surpassed by LCO.

As LFP achieved the second-best performance rating for stationary energy storage systems (besides the best price and criticality rating), it is extremely well suited for this kind of application. With the underlying weighting, LMO is ranked in second place. However, it is to be expected that by individually increasing the weighting of the performance category, NMC 111 and NMC 532 will outperform LMO as the preferable cathode chemistry. From the assessed NMC derivates, NMC 811 receives the worst substitutability rating. While NCA 9\% scores slightly better than NMC 811, the low-cobalt-containing NCA (NCA 3\%) is placed a distant second.

Both the low-cobalt-containing NCA and NMC improved their performance score for consumer electronics compared with stationary energy storage systems. Although all other cathode chemistries were downgraded concerning the fulfillment of the performance parameters, not much changed in the general ranking of substitutability. NMC 811 is to be preferred to NMC 111 and NMC 622 but in total only ranks the fourth-best option for consumer electronics. Once again, LCO is ranked last by far. This is interesting, as LCO cathodes are currently commonly used for applications in the field of consumer electronics [8].

The ranking for power and garden tools, as well as domestic appliances, is the same as for consumer electronics, although all cathode chemistries fulfill the performance requirements a little better than for consumer electronics (except for the NCA cathodes).

\section{Discussion}

Considering the three categories (criticality, price, and performance of the substitute), the results prove the LFP cathode chemistry's dominance in every field of application. Even the additional evaluation with the adjusted price of the cathode materials shows the same outcome. From a material perspective, LFP remains the cheapest cathode chemistry (even when taking the price adjustment into account). Nevertheless, it has to be stated that other publications assess either NMC or NCA as the cheapest option [62,76]. As this is not justifiable considering the material prices, it is to be expected that optimized and efficient production processes contribute significantly to the overall manufacturing costs of battery cells (both NMC and NCA were scored with the highest "maturity score" [62]). Differing statements about the performance and costs of cathode chemistries result in uncertainties concerning the substitutability assessment and also demonstrate the complexity of the research field. This is identified as one of the reasons for the contradicting results of this article with publications concerned with the future market shares of the discussed cathode chemistries. Until recently, a significant decrease in the market share of LFP was predicted $[77,78]$. Nevertheless, as Tesla announced the use of LFP batteries in at least a few of their models [79], other car manufacturers might reconsider their current choice of cathode material. This might eventuate in a renaissance of the LFP battery chemistry. This article reveals the potential benefits of and argumentative enablers for this possible future trend.

In the literature, NMC is predicted to become the predominant cathode chemistry in the near future $[8,77,78]$. While this cannot directly be derived from the results presented 
in this article, at least one derivate of the considered NMC chemistries is in the top three alternatives for every considered field of application. While being assessed with very good scores in the performance category, the high price of the comprised materials prevents a top overall scoring. As already discussed, this assessment might change by extending the material perspective to the overall production costs of battery cells [62,76]. The NMC chemistries with high cobalt material shares (NMC 111 and 532) are the only cathode chemistries that could fare better than LFP by an alteration of the categories' weighting (a decrease/an increase in the importance of the price/performance, respectively). It is interesting to see that the expected progress to nickel-rich NMC cathodes [8] cannot be derived from the results of the present article. This is mainly due to their poorer performance concerning the safety indicator. Additionally, the durability and maturity of nickel-rich cathode chemistries are not yet on the level of battery generation 2a (NMC 111). The resulting score in the performance category cannot be compensated for by respective better scorings in the price category. Variances in the standardization of the category scores (scaling from minimum to maximum instead of zero to maximum), as well as the separate analysis of the NMC derivates (with neglection of the other cathode chemistries), result in small alterations in the conclusions. NMC 532 remains the preferable and NMC 622 the least preferable NMC cathode. However, compared with the initial assessment, NMC 811 is scored with better substitutability than NMC 111 in two more fields of application (traction batteries and power-/garden tools).

The market share of NCA batteries remains constant according to the literature $[77,78]$. However, this prediction is based on the assumption that Tesla will continue to use NCA batteries to the extent they did at the time the respective literature was published [78]. As stated before, Tesla introduced LFP batteries into its product portfolio in 2020. Hence, it is to be expected that the market shares of NCA batteries will decrease in the future. This agrees with the findings of the presented work, as the results suggest the substitution of NCA in every field of application.

The unfavorable substitutability score of LCO is validated by the significant decrease in the respective predicted market shares $[77,78]$. LCO cathodes are advised to be substituted in every field of application due to the significant amounts of cobalt in the material composition of the cathode. Concerning the material shares, differing statements can be found in the literature. However, by replacing the applied share (compare the results on the elemental level), the supply risk, environmental impact, are social implications are aggregated to the cathode-specific technology level. This is done by weighing the obtained values by mass shares of the respective raw material (or precursor material) within the considered cathode chemistries. This approach to calculating the criticality of material compounds or products is accepted in the scientific community [30-32]. The material compositions of the individual cathode chemistries can be obtained from Table 2. Thereby, lithium and manganese are applied as different derivates for some cathode chemistries. While lithium carbonate is used for NMC 111, NMC 532, NMC 622, LMO, and LCO [56,57], lithium hydroxide is required for the nickel-rich cathode NMC 811, LFP, and the NCA technologies [57-59]. The NMC active material is comprised of manganese sulfate [57], while for LMO manganese dioxide is applied [60]. The respective information is involved for the environmental dimension. The indicators of the considered LCIA endpoint categories are assessed in both a raw-material-specific and derivate-specific manner. As no dataset exists for cobalt sulfate hexahydrate in the ecoinvent database [47], a mixed calculation from sulfuric acid and cobalt based on stoichiometric calculations was conducted.

Table 2 contains more progressive values $\left(1 / 3 \mathrm{Li}_{2} \mathrm{CO}_{3}\right.$ and 2/3 $\left.\mathrm{CoSO}_{4}\right)$; however, the ranking concerning the overall substitutability score is not altered. This is due to the fact that even then the cobalt share is still very high compared with the other cathode chemistries.

A summary of the factors that increase the uncertainty in the results is presented in the following. In addition, outlooks for potential further research are mentioned. 
The evaluation of the performance indicators is based on the acknowledged literature. Nevertheless, it has to be stated that the respective information is not consistent. An example is the scoring of the safety indicator. While Zubi et al. (who we use as the respective reference in this article) assess the NCA cathode as rather safe (1.5 points with a scale ranging from 0 to 2) [62], Meeus estimates the safety of NCA as being the lowest [76]. However, the estimate of Zubi et al. is supported by other references [80]. Another example of differing assessments can be observed for LMO cathodes. The costs, the energy, and the durability are scored rather differently. Expert interviews could reduce uncertainties concerning these aspects and are planned for further research. Additionally, the completeness of the considered performance indicators could be verified on this occasion (for example: is the temperature stability, which might be an important factor, especially for traction batteries, sufficiently covered by the durability indicator?)

The scoring for many indicators is fundamentally dependent on the material shares. As already discussed for LCO, differing statements concerning this aspect can be found in the literature. Hence, the results presented in this article should be seen as approximations. Detailed assessments must be conducted with the actual material shares of cathode chemistries utilized by the company that considers a substitution.

The price category has a relevant impact on the overall substitutability scoring of the considered cathode chemistries in all five fields of application. This article focuses only on the material prices and does not consider costs for the production of the battery cells and the respective manufacturing infrastructure. This is identified as a potential reason for partially significant differences between the price assessment in this article and the consulted literature [62,76]. The utilization of phosphate rock as the underlying material for the LFP price assessment is an inaccuracy worth mentioning. Due to this fact, an additional scenario with higher cathode prices for LFP derived from the literature was analyzed. Furthermore, the quality of historic data for the different cathode materials varies, which constitutes another potential source of uncertainty.

Criticality assessments are highly dependent on volatile data (e.g., the enormously increasing resources of lithium identified during the past few years). Consequently, criticality scores vary depending on the underlying base year. Hence, it is advisable to conduct such evaluations periodically. This is one of the reasons why the criticality of cathode chemistries was assessed in this article even though there are publications concerned with similar topics (compare [30,31]). In total, the criticality category has a relatively small impact on the selection of substitutes, as the scorings of the individual cathode chemistries do not differ significantly (with the biggest gap between LFP and LCO). This finding is in agreement with the work of Helbig et al. [30]. The integration of social and environmental aspects in addition to the dimension of supply risk does not change the result of small differences in the overall criticality scoring between the considered cathode chemistries.

In total, the assessment model presented in this article generates reasonable results that are consistent with the literature. Where this is not the case, the underlying reasons were identified and discussed. The introduced approach to evaluating the substitutability of LIB cathode chemistries is a basis for further research and sophistication. In particular, the company-specific adjustment of underlying data (for the price and performance categories) and the individual weighting of indicators and categories bear potential for increasing the applicability of the approach in the industry. Until then, the presented results, based on the described assumptions, provide a profound overview of the substitutability of cathode chemistries. The prospects for further research include the revision of the selected assumptions and the respective validation employing a broad expert survey. Particular focus in this regard should be put on the price category. The present article focuses on the material perspective. Hence, the applied indicators take the costs for the utilized raw materials into account and neglect the accompanying costs for producing the final composite material of the cathodes. The impact of a change from a raw material to a composite perspective in the price category should be analyzed in detail in further research. 
This study did not involve a detailed sensitivity analysis but investigates the impact of an alteration in the selected indicators. Monte Carlo simulations are widely applied in the literature in order to conduct sensitivity analyses in the context of criticality assessments. The application of this method to the presented approach to assessing the substitutability of cathode chemistries should also be part of further research.

Finally, other cathode chemistries could be added as potential substitutes. Examples include blends (e.g., LMO/NMC) that are likely to obtain a considerable market share in the foreseeable future [63].

\section{Conclusions}

This article provides a decision support model for increasing the sustainability of product portfolios. For this purpose, the substitutability of products and material compounds is assessed based on the material criticality, performance, and price of the substitute. Thereby, the state of the art is compared with potential substitutes. The approach involves a variety of selected and relevant indicators to enable the derivation of the individual benefits and disadvantages of each evaluated option.

For validation, the developed methodology was applied to state-of-the-art LIB cathode chemistries (NMC 111, NMC 532, NMC 622, NMC 811, NCA 3\%, NCA 9\%, LMO, LFP, and LCO) as LIBs are some of the most relevant emerging technologies in the debate on future material availability. The assessment was conducted in a use-case-specific manner (traction batteries, stationary energy storage systems, consumer electronics, power-/garden tools, and domestic appliances). The outcomes show that LFP is the preferable cathode chemistry while LCO obtains the worst rating for all fields of application. The ranking based on the substitutability score of the other cathode chemistries varies per field of application. NMC 532, NMC 811, NMC 111, and LMO are to be regarded as recommendable types of cathodes.

The obtained results agree partially with predictions concerning future market shares of LIB cathode chemistries. Deviations are to be examined in further research. Potential causes, as well as options for improving the introduced methodology, are identified in this article. The main reasons for potential uncertainties are the applied assumptions concerning the price and performance categories. The price indicators are material-specific and based partly on historical data. It remains to be determined whether the applicability of the considered data is the same for each assessed material as well as whether a switch to cathode-chemistry-specific (instead of material-specific) prices would be feasible. The results concerning the category "performance of the substitute" could be refined and qualified by a further expert survey.

Supplementary Materials: The following are available online at https:/ /www.mdpi.com/article/10 .3390/resources10090087/s1, Figure S1: Questionnaire for the AHP, Table S1: Raw material criticality of LIB cathode chemistries, Table S2: Raw material criticality of LIB cathode chemistries, normalized on a scale from 0 to the maximum value, Table S3: Performance of cathode chemistries, Table S4: Importance of technical criteria/indicators per field of application, Table S5: Weighted performance of cathode chemistries for selected fields of application, normalized on a scale from 0 to the maximum value, Table S6: Price information—raw material level, Table S7: Price information—cathode chemistry level, Table S8: Price of cathode chemistries, normalized on a scale from 0 to the maximum value, Table S9: Consulted experts for the AHP, Table S10. Consulted experts for the AHP-process.

Author Contributions: Conceptualization, S.K.; methodology, S.K. and S.G.-C.; validation, S.K., S.G.-C. and R.M.; data curation, S.K. and M.S.; writing—original draft preparation, S.K. and L.W.; writing-review and editing, S.K., S.G.-C., L.W., M.S., A.S., and R.M.; visualization, S.K.; supervision, A.S. and R.M. All authors have read and agreed to the published version of the manuscript.

Funding: This research was funded by the Ministry of Economic Affairs, Labour and Tourism of Baden-Württemberg, grant number 017-105082/B7-RI. 
Data Availability Statement: All data were obtained from publicly available literature sources and databases. The respective references are mentioned in the article. The only exceptions are selected indicators from the social dimension of the raw material criticality assessment. These were obtained from the fee-based "social hotspots database".

Acknowledgments: The authors would like to thank the external experts who returned a completed questionnaire for the AHP. These experts are, in alphabetical order, David Ensling, Johannes Full, Christoph Helbig, Sandra Huster, Gernot Kraberger, Sonja Rosenberg, Klaus Steinmüller, and Lars Wietschel.

Conflicts of Interest: The authors declare no conflict of interest. The funders had no role in the design of the study; in the collection, analyses, or interpretation of data; in the writing of the manuscript; or in the decision to publish the results.

\section{References}

1. United Nations. Paris Agreement; UN: New York, NY, USA, 2015; Available online: https://unfccc.int/process-and-meetings/theparis-agreement/the-paris-agreement (accessed on 30 July 2021).

2. European Commission. The European Green Deal. COM 640; European Commission: Brussels, Belgium, 2019; Available online: https: / / eur-lex.europa.eu/legal-content/EN/TXT/?qid=1576150542719\&uri=COM\%3A2019\%3A640\%3AFIN (accessed on 30 July 2021).

3. European Commission. 'Fit for 55': Delivering the EU's 2030 Climate Target on the Way to Climate Neutrality; COM(2021) 550 Final; European Commission: Brussels, Belgium, 2021; Available online: https:/ / eur-lex.europa.eu/legal-content/EN/TXT/?uri= CELEX:52021DC0550 (accessed on 30 July 2021).

4. Ritchie, H. Cars, Planes, Trains: Where Do $\mathrm{CO}_{2}$ Emissions from Transport Come from? 2020. Available online: https:// ourworldindata.org/co2-emissions-from-transport (accessed on 30 July 2021).

5. Zhang, R.; Fujimori, S. The role of transport electrification in global climate change mitigation scenarios. Environ. Res. Lett. 2020, 15. [CrossRef]

6. IEA. Energy Technology Perspectives 2020; International Energy Agency: Paris, France, 2020; Available online: https://www.iea. org/reports/energy-technology-perspectives-2020 (accessed on 30 July 2021).

7. Köse, E.; Sauer, A.; Pelzel, C. Energieflexibel durch bivalente Produktionsanlagen/Energy flexibility through bivalent production facilities-Using bivalent production processes to reduce energy costs and stabilize the electricity grid. Wt Werkstattstech. Online 2017, 107, 366-372. [CrossRef]

8. Merriman, D. The EV Revolution: Impacts on Critical Raw Material Supply Chains. 2019. Available online: https://www minersoc.org/wp-content/uploads/2019/05/3ICM-Merriman.pdf (accessed on 30 July 2021).

9. Karabelli, D.; Kiemel, S.; Singh, S.; Koller, J.; Ehrenberger, S.; Miehe, R.; Weeber, M.; Birke, K.P. Tackling xEV battery chemistry in view of raw material supply shortfalls. Front. Energy Res. 2020, 8. [CrossRef]

10. Olivetti, E.A.; Ceder, G.; Gaustad, G.G.; Fu, X. Lithium-ion battery supply chain considerations: Analysis of potential bottlenecks in critical metals. Joule 2017, 1, 229-243. [CrossRef]

11. Haglund, D.G. Strategic minerals: A conceptual analysis. Resour. Policy 1984, 10, 146-152. [CrossRef]

12. Erdmann, L.; Graedel, T.E. Criticality of non-fuel minerals: A review of major approaches and analyses. Environ. Sci. Technol. 2011, 45, 7620-7630. [CrossRef]

13. Graedel, T.E.; Barr, R.; Chandler, C.; Chase, T.; Choi, J.; Christoffersen, L.; Friedlander, E.; Henly, C.; Jun, C.; Nassar, N.T.; et al. Methodology of metal criticality determination. Environ. Sci. Technol. 2012, 46, 1063-1070. [CrossRef]

14. Kolotzek, C.; Helbig, C.; Thorenz, A.; Reller, A.; Tuma, A. A company-oriented model for the assessment of raw material supply risks, environmental impact and social implications. J. Clean. Prod. 2018, 176, 566-580. [CrossRef]

15. Miehe, R.; Schneider, R.; Baaij, F.; Bauernhansl, T. Criticality of material resources in industrial enterprises-Structural basics of an operational model. Procedia CIRP 2016, 48, 1-9. [CrossRef]

16. Schrijvers, D.; Hool, A.; Blengini, G.A.; Chen, W.-Q.; Dewulf, J.; Eggert, R.; van Ellen, L.; Gauss, R.; Goddin, J.; Habib, K.; et al. A review of methods and data to determine raw material criticality. Resour. Conserv. Recycl. 2020, 155, 104617. [CrossRef]

17. Panousi, S.; Harper, E.M.; Nuss, P.; Eckelman, M.J.; Hakimian, A.; Graedel, T.E. Criticality of Seven Specialty Metals. J. Ind. Ecol. 2016, 20, 837-853. [CrossRef]

18. Graedel, T.E.; Harper, E.M.; Nassar, N.T.; Nuss, P.; Reck, B.K. Criticality of metals and metalloids. Proc. Natl. Acad. Sci. USA 2015, 112, 4257-4262. [CrossRef]

19. U.S. Department of Energy. Critical Materials Strategy; U.S. Department of Energy: Washington, DC, USA, 2011.

20. European Commission. Study on the EU's List of Critical Raw Materials; Final Report; European Commission: Brussels, Belgium, 2020.

21. Nassar, N.T.; Barr, R.; Browning, M.; Diao, Z.; Friedlander, E.; Harper, E.M.; Henly, C.; Kavlak, G.; Kwatra, S.; Jun, C.; et al. Criticality of the geological copper family. Environ. Sci. Technol. 2012, 46, 1071-1078. [CrossRef]

22. Nuss, P.; Harper, E.M.; Nassar, N.T.; Reck, B.K.; Graedel, T.E. Criticality of iron and its principal alloying elements. Environ. Sci. Technol. 2014, 48, 4171-4177. [CrossRef] 
23. Nassar, N.T.; Du, X.; Graedel, T.E. Criticality of the Rare Earth Elements. J. Ind. Ecol. 2015, 19, 1044-1054. [CrossRef]

24. USGS. Mineral Commodity Summaries 2019; US Geological Survey: Reston, VA, USA, 2019. Available online: https://pubs.er.usgs. gov/publication/70202434 (accessed on 30 July 2021).

25. USGS. Mineral Commodity Summaries 2015; US Geological Survey: Reston, VA, USA, 2015. Available online: https://www.usgs. gov/centers/nmic/mineral-commodity-summaries (accessed on 30 July 2021).

26. Viebahn, P.; Soukup, O.; Samadi, S.; Teubler, J.; Wiesen, K.; Ritthoff, M. Assessing the need for critical minerals to shift the German energy system towards a high proportion of renewables. Renew. Sustain. Energy Rev. 2015, 49, 655-671. [CrossRef]

27. Helbig, C.; Bradshaw, A.M.; Kolotzek, C.; Thorenz, A.; Tuma, A. Supply risks associated with CdTe and CIGS thin-film photovoltaics. Appl. Energy 2016, 178, 422-433. [CrossRef]

28. Kiemel, S.; Smolinka, T.; Lehner, F.; Full, J.; Sauer, A.; Miehe, R. Critical materials for water electrolysers at the example of the energy transition in Germany. Int. J. Energy Res. 2021, 45, 9914-9935. [CrossRef]

29. Yu, Y. Assessing the criticality of minerals used in emerging technologies in China. PAN 2020, 36, 5-20. [CrossRef]

30. Helbig, C.; Bradshaw, A.M.; Wietschel, L.; Thorenz, A.; Tuma, A. Supply risks associated with lithium-ion battery materials. J. Clean. Prod. 2018, 172, 274-286. [CrossRef]

31. Wentker, M.; Greenwood, M.; Asaba, M.C.; Leker, J. A raw material criticality and environmental impact assessment of state-ofthe-art and post-lithium-ion cathode technologies. J. Energy Storage 2019, 26, 101022. [CrossRef]

32. Simon, B.; Ziemann, S.; Weil, M. Criticality of metals for electrochemical energy storage systems-Development towards a technology specific indicator. Metall. Res. Technol. 2014, 111, 191-200. [CrossRef]

33. Bach, V.; Finogenova, N.; Berger, M.; Winter, L.; Finkbeiner, M. Enhancing the assessment of critical resource use at the country level with the SCARCE method-Case study of Germany. Resour. Policy 2017, 53, 283-299. [CrossRef]

34. Pavel, C.; Marmier, A.; Alves Dias, P.; Blagoeva, D.; Tzimas, E.; Schüler, D.; Schleicher, T.; Jenseit, W.; Degreif, S.; Buchert, M Substitution of Critical Raw Materials in Low-Carbon Technologies: Lighting, Wind Turbines and Electric Vehicles; Publications Office of the European Union: Luxembourg, 2016.

35. Halme, K.; Piirainen, K.; Vekinis, G.; Sievers, U.; Viljamaa, K. Substitutionability of Critical Raw Materials; European Parliament's Committee on Industry: Brussels, Belgium, 2012; Available online: https://op.europa.eu/de/publication-detail/-/publication/ 36145a5a-2da8-4730-9b69-4b5eb7444b25 (accessed on 30 July 2021).

36. Full, J.; Wanner, J.; Kiemel, S.; Miehe, R.; Weeber, M.; Sauer, A. Comparing technical criteria of various lithium-ion battery cell formats for deriving respective market potentials. In Proceedings of the 2020 IEEE Electric Power and Energy Conference (EPEC), Edmonton, AB, Canada, 9 November 2020; pp. 1-6. [CrossRef]

37. Achzet, B.; Helbig, C. How to evaluate raw material supply risks-An overview. Resour. Policy 2013, 38, 435-437. [CrossRef]

38. Goedkoop, M.; Heijungs, R.; Huijbregts, M.; de Schreyver, A.; Struijs, J.; van Zelm, R. ReCiPe 2008 A life Cycle Impact Assessment Method which Comprises Harmonised Category Indicators at the Midpoint and the Endpoint Level. Report I: Characterisation, 1st ed.; Ministerie van VROM: Den Haag, The Netherlands, 2009; Available online: https:/ /www.leidenuniv.nl/cml/ssp/publications/ recipe_characterisation.pdf (accessed on 30 July 2021).

39. Buchholz, P. Angebotskonzentration bei Mineralischen Rohstoffen und Zwischenprodukten—Potenzielle Preis- und Lieferrisiken: DERARohstoffliste 2012; DERA Rohstoffinformationen 24; DERA: Hannover, Germany, 2014.

40. Stedman, A.; Green, K.P. Fraser Institute Annual. Survey of Mining Companies 2018; Fraser Institute: Vancouver, BC, Canada, 2019.

41. Kaufmann, D.; Kraay, A.; Mastruzzi, M. The Worldwide Governance Indicators Project: Answering the Critics; Policy Research Working Paper No. 4149; World Bank: Washington, DC, USA, 2007; Available online: https:/ / openknowledge.worldbank.org/handle/10 986/7203 (accessed on 30 July 2021).

42. UNDP. Human Development Index. 2019. Available online: http://hdr.undp.org/en/content/human-development-index-hdi (accessed on 30 July 2021).

43. Nassar, N.T.; Graedel, T.E.; Harper, E.M. By-product metals are technologically essential but have problematic supply. Sci. Adv. 2015, 1, e1400180. [CrossRef] [PubMed]

44. Marscheider-Weidemann, F.; Langkau, S.; Hummen, T.; Erdmann, L.; Tercero Espinoza, L.A.; Angerer, G.; Marwede, M.; Benecke, S. Rohstoffe für Zukunftstechnologien 2016: Auftragsstudie; DERA Rohstoffinformationen 28; DERA: Hannover, Germany, 2016.

45. Graedel, T.E.; Harper, E.M.; Nassar, N.T.; Reck, B.K. On the materials basis of modern society. Proc. Natl. Acad. Sci. USA 2015, 112, 6295-6300. [CrossRef] [PubMed]

46. Graedel, T.E.; Allwood, J.; Birat, J.-P.; Buchert, M.; Hagelüken, C.; Reck, B.K.; Sibley, S.F.; Sonnemann, G. What do we know about metal recycling rates? J. Ind. Ecol. 2011, 15, 355-366. [CrossRef]

47. Wernet, G.; Bauer, C.; Steubing, B.; Reinhard, J.; Moreno-Ruiz, E.; Weidema, B. The ecoinvent database version 3 (part I): Overview and methodology. Int. J. Life Cycle Assess 2016, 21, 1218-1230. [CrossRef]

48. Kaufmann, D.; Kraay, A.; Mastruzzi, M. The Worldwide Governance Indicators, 2019 Update. Aggregate Governance Indicators 1996-2018; World Bank: Washington, DC, USA, 2019; Available online: https://info.worldbank.org/governance/wgi/ (accessed on 30 July 2021).

49. Schwab, K. The Global Competitiveness Report. Insight Report; World Economic Forum: Geneva, Switzerland, 2019; Available online: https:/ / www.weforum.org/reports/how-to-end-a-decade-of-lost-productivity-growth (accessed on 30 July 2021). 
50. Wendling, Z.; Emerson, J.; Esty, D.C.; Levy, M.A.; Sherbinin, A. Environmental Performance Index; Global Metrics for the Environment: Ranking Country Performance on High-Priority Environmental Issues; Yale Center for Environmental Law \& Policy: New Haven, CT, USA, 2018. [CrossRef]

51. The Fund for Peace. Fragile State Index 2019. 2019. Available online: https://fragilestatesindex.org/excel/ (accessed on 30 July 2021).

52. New Earth/Social Hotspots Database Project. 2021. Available online: http:/ / www.socialhotspot.org/ (accessed on 30 July 2021).

53. World Health Organization. Global Health Estimates 2016: Disease Burden by Cause, Age, Sex, by Country and by Region, 2000-2016; WHO: Geneva, Switzerland, 2018; Available online: http:/ / www.who.int/healthinfo/global_burden_disease/en/ (accessed on 30 July 2021).

54. Heidelberg Institute for International Conflict Research. Conflict Barometer 2018. 2019. Available online: https://hiik.de/2019/0 2/26/ konfliktbarometer-2018/ (accessed on 30 July 2021).

55. UNDP. Gender Inequality Index. 2018. Available online: http://hdr.undp.org/en/content/gender-inequality-index-gii (accessed on 30 July 2021).

56. Dunn, J.B.; James, C.; Gaines, L.; Gallagher, K.; Dai, Q.; Kelly, J.C. Material and Energy Flows in the Production of Cathode and Anode Materials for Lithium Ion Batteries; Argonne National Laboratory: Argonne, IL, USA, 2015. Available online: https: / / greet.es.anl.gov/publication-anode-cathode-liion (accessed on 30 July 2021).

57. Dai, Q.; Kelly, J.C.; Dunn, J.B.; Benavides, P.T. Update of Bill-of-Materials and Cathode Materials Production for Lithium-ion Batteries in the GREET Model; Argonne National Laboratory: Argonne, IL, USA, 2018. Available online: https://greet.es.anl.gov/publicationupdate_bom_cm (accessed on 30 July 2021).

58. Benavides, P.T.; Dai, Q.; Kelly, J.; Dunn, J.B. Addition of Nickel Cobalt Aluminum (NCA) Cathode Material to GREET2; Argonne National Laboratory: Argonne, IL, USA, 2016. Available online: https://greet.es.anl.gov/publication-NCA-Cathode-2016 (accessed on 30 July 2021).

59. Xie, J.; Gao, F.; Gong, X.; Wang, Z.; Liu, Y.; Sun, B. Life cycle assessment of LFP cathode material production for power lithium-ion batteries. In Advances in Energy and Environmental Materials. In Advances in Energy and Environmental Materials; Han, Y., Ed.; Springer: Singapore, 2017; pp. 513-522. [CrossRef]

60. Notter, D.A.; Gauch, M.; Widmer, R.; Wäger, P.; Stamp, A.; Zah, R.; Althaus, H.-J. Contribution of Li-ion batteries to the environmental impact of electric vehicles. Environ. Sci. Technol. 2010, 44. [CrossRef]

61. Lu, Q.; Wu, P.F.; Shen, W.X.; Wang, X.C.; Zhang, B.; Wang, C. Life cycle assessment of electric vehicle power battery. Mater. Sci. Forum 2016, 847, 403-410. [CrossRef]

62. Zubi, G.; Dufo-López, R.; Carvalho, M.; Pasaoglu, G. The lithium-ion battery: State of the art and future perspectives. Renew. Sustain. Energy Rev. 2018, 89, 292-308. [CrossRef]

63. Ding, Y.; Cano, Z.P.; Yu, A.; Lu, J.; Chen, Z. Automotive Li-Ion batteries: Current status and future perspectives. Electrochem. Energ. Rev. 2019, 2, 1-28. [CrossRef]

64. Li, M. and Lu, J. Cobalt in lithium-ion batteries. Science 2020, 367, 979-980. [CrossRef] [PubMed]

65. Croy, J.R.; Long, B.R.; Balasubramanian, M. A path toward cobalt-free lithium-ion cathodes. J. Power Sources 2019, $440,227113$. [CrossRef]

66. Wood, M.; Li, J.; Ruther, R.E.; Du, Z.; Self, E.C.; Meyer, H.M.; Daniel, C.; Belharouak, I.; Wood, D.L. Chemical stability and long-term cell performance of low-cobalt, Ni-Rich cathodes prepared by aqueous processing for high-energy Li-Ion batteries. Energy Storage Mater. 2020, 24, 188-197. [CrossRef]

67. Zhang, S.S. Problems and their origins of Ni-rich layered oxide cathode materials. Energy Storage Mater. 2020, 24, 247-254. [CrossRef]

68. DERA; BGR. Preismonitor. Dezember 2019; Deutsche Rohstoffagentur-Bundesanstalt für Geowissenschaften und Rohstoffe: Berlin, Germany, 2019; Available online: https://www.deutsche-rohstoffagentur.de/DE/Themen/Min_rohstoffe/Produkte/ Preisliste/pm_19_12.pdf?__blob=publicationFile\&v=5 (accessed on 30 July 2021).

69. Shulga, M. US Pig Iron: Prices Go Down on Weakening Scrap Market. 2018. Available online: https:/ /www.metalbulletin.com/ Article/3825289/US-PIG-IRON-Prices-go-down-on-weakening-scrap-market.html (accessed on 30 July 2021).

70. Kelly, T.D.; Matos, G.R.; Buckingham, D.A.; DiFrancesco, C.A.; Porter, K.E. Historical Statistics for Mineral and Material Commodities in the United States. 2017-2018. Available online: https://www.usgs.gov/centers/nmic/historical-statisticsmineral-and-material-commodities-united-states (accessed on 30 July 2021).

71. Connors, L.A.; Hayward, B.E. Trading für Profis. Mit Welchen Börsentechniken Sie von der Dummheit Vieler Anleger Profitieren; Börsenverl: Rosenheim, Germany, 1998.

72. Saaty, T.L.; Vargas, L.G. Decision Making in Economic, Political, Social and Technological Environments. With the Analytic Hierarchy Process; The Analytic Hierarchy Process Series 7; RWS Publication: Pittsburgh, PA, USA, 1994.

73. Meixner, O.; Haas, R. Wissensmanagement und Entscheidungstheorie: Mit 35 Tabellen; Facultas: Vienna, Austria, 2010.

74. Velázquez-Martínez, V.; Santasalo-Aarnio, R.; Serna-Guerrero, R. A critical review of lithium-ion battery recycling processes from a circular economy perspective. Batteries 2019, 5, 68. [CrossRef]

75. Rudisuela, K. Battle of the batteries-Cost versus Performance. 2020. Available online: https://nickelinstitute.org/blog/2020 /june/battle-of-the-batteries-cost-versus-performance/ (accessed on 17 July 2021). 
76. Meeus, M. Overview of battery cell technologies. In Proceedings of the European Battery Cell R\&I Workshop, Brussels, Belgium, 11-12 January 2018.

77. Pillot, C. Impact of the xEV market growth on lithium-ion batteries and raw materials supply 2018-2030. In Proceedings of the Automotive Battery Conference, Strasbourg, France, 27-31 January 2019; Available online: https: / /www.emove360.com/wpcontent/uploads/2019/10/Impact-of-the-xEV-Market-growth-on-Lithium-Ion-batteries-and-raw-matterials-supply-2018-2 030.pdf (accessed on 30 July 2021).

78. Or, T.; Gourley, S.W.D.; Kaliyappan, K.; Yu, A.; Chen, Z. Recycling of mixed cathode lithium-ion batteries for electric vehicles: Current status and future outlook. Carbon Energy 2020, 2, 6-43. [CrossRef]

79. Anderson, M. EV batteries shift into high gear: Advances in anodes, cathodes, and electrolytes are poised to appear in future electric vehicles. IEEE Spectr. 2020, 57, 8-9. [CrossRef]

80. Yoshio, M.; Brodd, R.J.; Kozawa, A. Lithium-Ion Batteries. Science and Technologies; Springer: New York, NY, USA, 2009; Available online: https://www.researchgate.net/publication/253140965_A_Review_of_Positive_Electrode_Materials_for_Lithium-Ion_ Batteries (accessed on 30 July 2021). 